\title{
Temporal Dynamics of L5 Dendrites in Medial Prefrontal Cortex Regulate Integration Versus Coincidence Detection of Afferent Inputs
}

\author{
Nikolai C. Dembrow, $\odot$ Boris V. Zemelman, and $\odot$ Daniel Johnston \\ Center for Learning and Memory, The University of Texas at Austin, Austin, Texas 78712
}

\begin{abstract}
Distinct brain regions are highly interconnected via long-range projections. How this inter-regional communication occurs depends not only upon which subsets of postsynaptic neurons receive input, but also, and equally importantly, upon what cellular subcompartments the projections target. Neocortical pyramidal neurons receive input onto their apical dendrites. However, physiological characterization of these inputs thus far has been exclusively somatocentric, leaving how the dendrites respond to spatial and temporal patterns of input unexplored. Here we used a combination of optogenetics with multisite electrode recordings to simultaneously measure dendritic and somatic responses to afferent fiber activation in two different populations of layer 5 (L5) pyramidal neurons in the rat medial prefrontal cortex (mPFC). We found that commissural inputs evoked monosynaptic responses in both intratelencephalic (IT) and pyramidal tract (PT) dendrites, whereas monosynaptic hippocampal input primarily targeted IT, but not PT, dendrites. To understand the role of dendritic integration in the processing of long-range inputs, we used dynamic clamp to simulate synaptic currents in the dendrites. IT dendrites functioned as temporal integrators that were particularly responsive to dendritic inputs within the gamma frequency range $(40-140 \mathrm{~Hz})$. In contrast, PT dendrites acted as coincidence detectors by responding to spatially distributed signals within a narrow time window. Thus, the PFC extracts information from different brain regions through the combination of selective dendritic targeting and the distinct dendritic physiological properties of L5 pyramidal dendrites.
\end{abstract}

Key words: channel rhodopsin 2; dendritic integration; prefrontal cortex; projection neurons

\section{Introduction}

To guide complex goal-directed behavior, the prefrontal cortex (PFC) integrates information from numerous cortical and subcortical regions. Two important afferent inputs that the PFC integrates derive from the hippocampus and the contralateral PFC. Damage to either is implicated in mental disorders (Godsil et al., 2013; Hoppenbrouwers et al., 2014; Wheeler et al., 2014), and their disruption is associated with deficits in performance on working memory-like tasks (Miu et al., 2006; Tseng et al., 2008; Dickerson et al., 2010; Sigurdsson et al., 2010). The timing of hippocampal inputs to the PFC is particularly important, as hippocampal-PFC synchrony elevates at the "decision point" in several learned tasks (Benchenane et al., 2010; Sigurdsson et al.,

\footnotetext{
Received Nov. 11, 2014; revised Jan. 7, 2015; accepted Jan. 27, 2015.

Author contributions: N.C.D. and D.J. designed research; N.C.D. performed research; B.V.Z. contributed unpublished reagents/analytic tools; N.C.D. analyzed data; N.C.D., B.V.Z., and D.J. wrote the paper.

This work was supported by National Institute of Mental Health Grants MH048432 and MH094839 and a Memory and Cognitive Disorders Award from the McKnight Foundation to D.J. and Michael Mauk, the Human Frontiers Science Program to B.V.Z., and a Brain \& Behavior Foundation Young Investigator award from the Walter K. Sartory Estate to N.C.D. Special thanks to Eedann McCord and Moriah Gottman for performing surgeries; Drs. Sachin Vaidya and Richard Gray for help and input on implementing dynamic-clamp, transfer, and wavelet analysis code; and Drs. Raymond Chitwood, Brian Kalmbach, and Darrin Brager for discussions and input pertaining to this project.

The authors declare no competing financial interests.

Correspondence should be addressed to Nikolai Dembrow, Center for Learning and Memory, the University of Texas at Austin, 1 University Station Stop C7000, Austin, TX 78712-0805. E-mail: nikolai@ca1.clm.utexas.edu. DOI:10.1523/JNEUROSCI.4673-14.2015

Copyright $\odot 2015$ the authors $\quad 0270-6474 / 15 / 354501-14 \$ 15.00 / 0$
}

2010; Adhikari et al., 2011; Fujisawa and Buzsáki, 2011). How long-range afferent inputs are able to influence PFC activity depends greatly on what neuron subpopulations they target.

Commissural and hippocampal afferent fibers are distributed across cellular layers, and thus may target several pyramidal and interneuron populations (Jay et al., 1989; Hoover and Vertes, 2007). Supragranular (layers 1-3) inputs target the apical dendrites and perisomatic regions of layer 2 pyramidal neurons (Little and Carter, 2012). Whether these inputs also target layer 5 (L5) pyramidal neurons' apical dendrites is not known. A further complication is that L5 pyramidal neurons can be separated into two categories: (1) pyramidal tract (PT) neurons, which project subcortically via the pyramidal tracts, and (2) intratelencaphalic (IT) neurons, which project across the cerebral commissure. PT and IT neurons make and receive different local connections within the PFC and are distinct electrophysiologically and anatomically (Morishima and Kawaguchi, 2006; Otsuka and Kawaguchi, 2008; Dembrow et al., 2010). While PT and IT neurons have both been shown to respond to activation of commissural fibers en masse, whether these inputs are monosynaptic and whether they target the dendrites remains uncertain (Lee et al., 2014). In both the PFC and other cortical regions, supragranular input to L5 pyramidal neurons has only been tested using somatic recordings, where it elicits little or no response (Petreanu et al., 2007; Anderson et al., 2010; Oviedo et al., 2010; Mao et al., 2011; Sheets et al., 2011; Lee et al., 2014). It remains unclear whether 
this is because long-range supragranular terminals do not innervate L5 pyramidal neurons or because filtering obscures dendritic responses.

Using simultaneous dendritic and somatic recordings, we have found that L5 neurons in medial PFC (mPFC) received substantial dendritic input from long-range afferent fibers. Whether these inputs directly targeted the dendritic compartment depended upon the afferent fiber type and the postsynaptic neuron identity. Furthermore, how PT and IT neurons processed simulated synaptic input made them sensitive to different spatial and temporal patterns of input. IT neurons summated synaptic input across a broader temporal window but with significant temporal distortion. Meanwhile, PT dendrites were highly responsive to spatially distributed signals within a narrow temporal window, and thus could act as coincidence detectors. Our data suggest that how inputs communicated to the mPFC microcircuit would depend upon the filtering properties of the dendritic subcompartments they targeted.

\section{Materials and Methods}

Surgeries. All procedures involving animals were performed with the approval of the University of Texas Animal Care and Use Committee. Male Sprague Dawley rats 9-15 weeks old were anesthetized with isoflurane (1-4\% mixed in oxygen), placed in a stereotaxic apparatus, and prepped for injections with craniotomies over the target injection regions. Injections were performed using a pulled glass pipette $(10-15 \mu \mathrm{m}$ diameter tip) mounted on a Nanoject II small-volume injector (Drummond Scientific). Each individual injection was performed at a speed of $23 \mathrm{~nL} / \mathrm{s}$, separated by a 2-3 min interval. Recombinant adeno-associated virus (rAAV)-expressing channel-rhodopsin2-sfGFP (ChR2) from a synapsin promoter was injected into either the contralateral PFC (2.5$3.5 \mathrm{~mm}$ anterior, $0.7-0.8 \mathrm{~mm}$ lateral, and $3.5-4.4 \mathrm{~mm}$ ventral to bregma; six injections; $13.8 \mathrm{~nL}$ each) or the ipsilateral ventral hippocampus (6.3 $\mathrm{mm}$ anterior, $5.7 \mathrm{~mm}$ lateral, $5.8-6.8 \mathrm{~mm}$ ventral to bregma; eight 13.8 $\mathrm{nL}$ injections separated ventrally by $150 \mu \mathrm{m})$. Red fluorescent-labeled microspheres (Lumafluor) were injected into either the pons (right; 7.4 $\mathrm{mm}$ posterior, $1.1 \mathrm{~mm}$ lateral, $9.8 \mathrm{~mm}$ ventral to bregma; $2-3$ injections in same location; $50.6 \mathrm{~nL}$ each) or mPFC (left; $2.5-3.5 \mathrm{~mm}$ anterior, 0.8 $\mathrm{mm}$ lateral, and $4-4.4 \mathrm{~mm}$ ventral to bregma; two injections; $50.6 \mathrm{~nL}$ each) to retrogradely label corticopontine PT and commissural IT neurons, respectively. For all injections, the pipette was left in place for 3-5 min before removing it from the brain. Rats were given analgesics (carprofen; $5 \mathrm{mg} / \mathrm{kg}$ ) postsurgery, and monitored daily to ensure complete recovery. For virally injected animals, viral expression was allowed for 7-12 weeks after surgery before collecting tissue.

Slice preparation. Male Sprague Dawley rats 10-20 weeks old were anesthetized using a ketamine $(100 \mathrm{mg} / \mathrm{kg}) /$ xylazine $(10 \mathrm{mg} / \mathrm{kg})$ mixture delivered intraperitoneally. Rats were perfused through the heart with ice-cold saline containing the following (in mM): $2.5 \mathrm{KCl}, 1.25 \mathrm{NaH}_{2} \mathrm{PO}_{4}$, $25 \mathrm{NaHCO}_{3}, 0.5 \mathrm{CaCl}_{2}, 7 \mathrm{MgCl}_{2}, 7$ dextrose, 205 sucrose, 1.3 ascorbate, and 3 sodium pyruvate (bubbled with $95 \% \mathrm{O}_{2} / 5 \% \mathrm{CO}_{2}$ to maintain $\mathrm{pH}$ at 7.4). Brains were removed, and a blocking cut was made $11^{\circ}$ off coronal to maintain the plane of the dendrites within the slice. Using a vibrating tissue slicer (Vibratome 3000, Vibratome), 300- $\mu \mathrm{m}$-thick coronal sections were collected from $2.5 \mathrm{~mm}$ and up to the fusion of the genii of the corpus callosum. Slices were cut in ice-cold saline that was identical to the saline used during the perfusion, subsequently stored in holding solution containing the following (in mM): $125 \mathrm{NaCl}, 2.5 \mathrm{KCl}, 1.25 \mathrm{NaH}_{2} \mathrm{PO}_{4}, 25$ $\mathrm{NaHCO}_{3}, 2 \mathrm{CaCl}_{2}, 2 \mathrm{MgCl}_{2}, 12.5$ dextrose, and 3 sodium pyruvate (bubbled with $95 \% \mathrm{O}_{2} / 5 \% \mathrm{CO}_{2}$ ) at $35^{\circ} \mathrm{C}$ for $30 \mathrm{~min}$, and then at room temperature. In cases where tissue contained ChR2-EYFP-expressing neurons, great care was taken to minimize light exposure during slicing, tissue storage, and recording.

Recording and light stimulation. For recording, slices were continuously perfused (1-2 $\mathrm{mL} / \mathrm{min}$ ) with ACSF containing the following (in mM): $125 \mathrm{NaCl}, 3.0 \mathrm{KCl}, 1.25 \mathrm{NaH}_{2} \mathrm{PO}_{4}, 25 \mathrm{NaHCO}_{3}, 2 \mathrm{CaCl}_{2}, 1 \mathrm{MgCl}_{2}$, and 12.5 dextrose bubbled continuously with $95 \% \mathrm{O}_{2} / 5 \% \mathrm{CO}_{2}$ at $32-$ $35^{\circ} \mathrm{C}$. Neurons were visualized using either a Zeiss Axioskop with infrared video microscopy and differential interference contrast optics or a resonant scanning Leica two-photon system (with Dodt contrast). Somatic patch pipettes $(4-6 \mathrm{M} \Omega$ ) were filled with an internal solution containing the following (in $\mathrm{mm}$ ): $120 \mathrm{~K}$-gluconate, $16 \mathrm{KCl}, 10 \mathrm{HEPES}, 8$ $\mathrm{NaCl}, 4 \mathrm{MgATP}, 0.3 \mathrm{NaGTP}$, and $7 \mathrm{~K}_{2}$-phosphocreatine, pH 7.3 with $\mathrm{KOH}$, with neurobiotin $(0.1-0.2 \%)$ and Alexa-594 (20-40 $\mu \mathrm{M})$. Beadlabeled neurons or Alexa-594-filled neurons were visualized using either two-photon excitation at $840 \mathrm{~nm}$ or light from a mercury lamp (X-Cite, Lumen Dynamics) passed through a 540/605 nm excitation/emission filter set. Simultaneous soma and dendrite recordings were made by first patching the soma of an L5 neuron with a pipette containing Alexa-594 $(40 \mu \mathrm{M})$. This permitted the dendrite to be visualized and subsequently patched with a dendritic patch pipette $(6-10 \mathrm{M} \Omega)$ using simultaneous Dodt contrast and fluorescence microscopy. Dendritic pipettes were wrapped with Parafilm to minimize capacitance. For a subset of the dual recordings, we categorized IT versus PT neurons from one another using the neurons' somatic and dendritic electrophysiological properties. As established by our previous reports (Dembrow et al., 2010; Kalmbach et al., 2013), PT neurons display somatic resonance of $>2.2 \mathrm{~Hz}$ and dendritic resonance of $>5 \mathrm{~Hz}$.

Electrophysiological data were acquired using either a Dagan BVC700 (Dagan) amplifier with custom data-acquisition software written using Igor Pro (Wavemetrics) or a Multiclamp 700B (Molecular Devices) amplifier with AxoGraph X (AxoGraph Scientific) data-acquisition software. Data were acquired at $10-50 \mathrm{kHz}$, filtered at $5-10 \mathrm{kHz}$, and digitized by an ITC-18 (InstruTech) interface. Pipette capacitance was compensated, and the bridge was balanced with each recording. Series resistance was monitored throughout each experiment and was 10-25 $\mathrm{M} \Omega$ for somatic recordings and 15-45 $\mathrm{M} \Omega$ for dendritic recordings. Voltages are not corrected for the liquid-junction potential (estimated as $\sim 12 \mathrm{mV}$ based on relative ionic mobilities and charge).

ChR2 inputs were triggered by field illumination (Thorlabs LED; $1 \mathrm{~ms}$, $0.2-3.5 \mathrm{~mW}$ at focal plane) focused through a $20 \times(740 \mu \mathrm{m}$ diameter $)$ or a $60 \times(225 \mu \mathrm{m}$ diameter $)$ objective. For a subset of experiments where smaller field of illumination was needed, an internal iris prior to the $20 \times$ objective reduced the spot size to a circle $210 \mu \mathrm{m}$ in diameter or a rectangle measuring $260 \times 390 \mu \mathrm{m}$. Each trial of light illumination was separated by $1 \mathrm{~min}$, to minimize any potential plasticity or release rundown. For all tests of monosynaptic responses, the minimal light intensity stimulation was used that was sufficient to drive three concurrent responses. Using this same level of illumination, $1.25 \mu \mathrm{M} \mathrm{D}-2$-amino-5phonovalerate (D-APV) and $1 \mu \mathrm{M}$ DNQX were bath applied for $15 \mathrm{~min}$ while responses every minute were monitored. To examine terminal release, $1 \mu \mathrm{M}$ TTX and $100 \mu \mathrm{M}$ 4-AP were bath applied. In some cases, increasing the light stimulation ( $2-5 \mathrm{~ms}$ light exposure) was necessary to observe responses. Within each neuron, light intensity was kept consistent for all subcompartments illuminated.

Dynamic clamp. Synaptic currents were simulated using dynamic clamp as described by Vaidya and Johnston (2013). Briefly, the dynamicclamp system was implemented by StdpC software on a standard PC (Intel Core 2 Duo E8400; 3 GHz with 2 GB RAM) and Windows 7 (64 bit) interfaced using a National Instruments acquisition card (PCIe-6251) via a connector block (BNC-2210) and a unity gain amplifier. Experiments were performed at an update speed of $10 \mathrm{kHz}$. Synaptic events were signaled by a $0.1 \mathrm{~ms}$ transistor-transistor logic pulse from Axograph during current or voltage-clamp acquisition. This pulse drove the "presynaptic" simulated neuron in StdpC (with a voltage threshold of $50 \mathrm{mV}$ and voltage slope of $25 \mathrm{mV}$ ) to produce a synaptic conductance with a near-instantaneous rise to its maximum value (set at 1-10 nS), followed by a single exponential decay (set to $2 \mathrm{~ms}$ ). The reversal potential of the synaptic conductance was set at $0 \mathrm{mV}$. Conductance and decay times were chosen as they best fit light-evoked responses observed in the dendrites.

Analysis and statistics. To analyze the relative power of frequency components within current and voltage waveforms, we used the continuous wavelet transform (CWT) as described by Vaidya and Johnston (2013). CWT was performed using a complex Morlet wavelet implemented in Igor Pro (Wavemetrics) following guidelines from Torrence and Compo 
(1998). The transform coefficients for power were corrected for their energy bias to allow comparison across frequencies. We report the average of the frequency spectrum across the time series as a "global average" to permit comparisons across cell types. For both neuron types, the global average satisfactorily represented the spectral components of simulated synaptic events across the time series. Paired $t$ tests, ANOVA with repeated measures, or mixed-factor ANOVA, ANCOVA, and post hoc $t$ tests with Bonferonni's correction were used to test for statistical differences between conditions. Error bars represent SEM. Analyses and graphing were performed with a combination of Axograph, Excel, and Igor. Statistical tests were performed in R and/or Prism (GraphPad).

Drugs. Drugs were prepared from concentrated stock solutions in water [gabazine, DNQX, D-APV, 4-AP, TTX, 4-ethylphenyl-amino-1,2dimethyl-6-methylaminopyrimidinium chloride (ZD7288)] or DMSO (CGP55845; final concentration of DMSO, $<0.1 \%$ ) as appropriate stored at $-20^{\circ} \mathrm{C}$. All drugs were obtained from Abcam.

\section{Results}

Commissural and hippocampal inputs to prefrontal neurons To examine how hippocampal and commissural afferents target the mPFC in the rat, we delivered rAAV expressing ChR2-sfGFP to either the contralateral PFC (Fig. 1a) or the ipsilateral ventral hippocampus (Fig. 1b). By 3 weeks, fluorescent commissural axons and terminals were visible throughout the cortical layers, but were most dense within L1B and L5B (Fig. 1c,e). Hippocampal innervation was sparser than commissural input (Fig. 1d,f). Hippocampal fibers were densest in the more ventral regions of $\mathrm{mPFC}$ (prelimbic and infralimbic cortex) and did not extend to anterior cingulate or agranular motor cortex. In prelimbic cortex, hippocampal fibers formed two broader bands of labeling, one supragranular and one infragranular (Fig. 1d). The dendritic arbors of L5 pyramidal neurons (filled with 20-40 $\mu$ M Alexa-594) extended throughout the same regions that both commissural (Fig. 1e) and hippocampal (Fig. 1f) fibers innervated. Thus, in addition to making contacts proximal to the soma, hippocampal and commissural axons may potentially synapse on L5 pyramidal neurons throughout the cortical layers. Previous reports both in anesthetized animals in vivo and in slices ex vivo demonstrated that stimulating hippocampal and commissural inputs can elicit synaptic responses in L5 neurons (Cowan and Wilson, 1994; Dégenètais et al., 2003; Parent et al., 2010; Lee et al., 2014). To confirm that L5 mPFC neurons elicited responses at the soma, we briefly illuminated the whole field ( $1 \mathrm{~ms}, 0.2-2.5 \mathrm{~mW}$ ). Commissural inputs elicited responses in all PT neurons (13 of 13) and most IT neurons (13 of 19). Hippocampal inputs selectively targeted IT neurons: fiber activation elicited responses in fewer PT neurons (12 of 21) than IT neurons (23 of 31).

While previous reports have shown that fiber activation can elicit responses in L5 neurons, it remained unclear whether these inputs were monosynaptic. Hippocampal and commissural inputs both directly synapse onto L2 neurons, which are capable of providing feedforward excitation to L5 neurons (Little and Carter, 2012; Otsuka and Kawaguchi, 2008). Thus, these longrange afferent inputs might be indirect: processed first by the supragranular pyramidal neurons before reaching the primary output layer (L5) of the mPFC. To test whether observed responses were monosynaptic, we minimized the recruitment of local neurons with low concentrations of AMPA and NMDA receptor blockers ( $2.5 \mu \mathrm{M}$ D-AP5, $2 \mu \mathrm{M}$ DNQX). Responses that were eliminated in an all-or-none fashion were presumed to be polysynaptic, while responses that were reduced in amplitude but that nevertheless persisted were presumed to be monosynaptic (hippocampal to IT: $66.4 \pm 14.9 \%, n=13$; hippocampal to PT: a

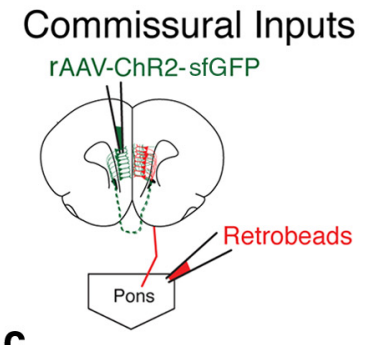

C
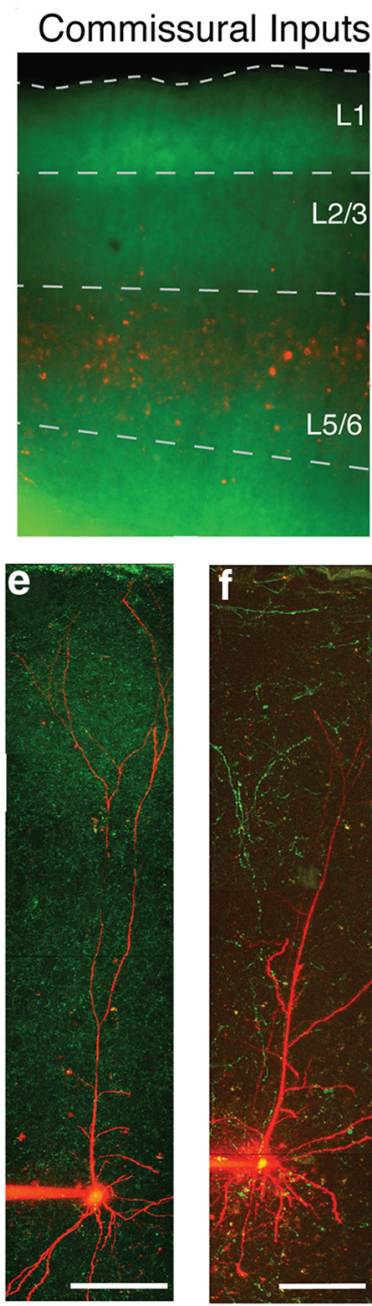

Commissural Inputs

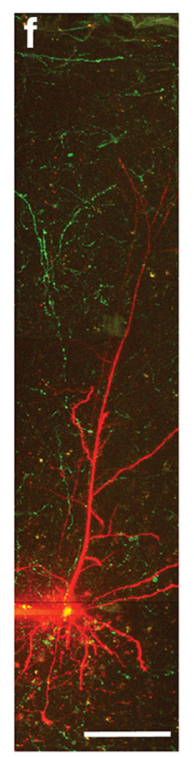

Hippocampal Inputs b

Hippocampal Inputs

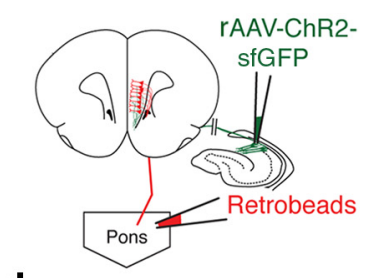

d
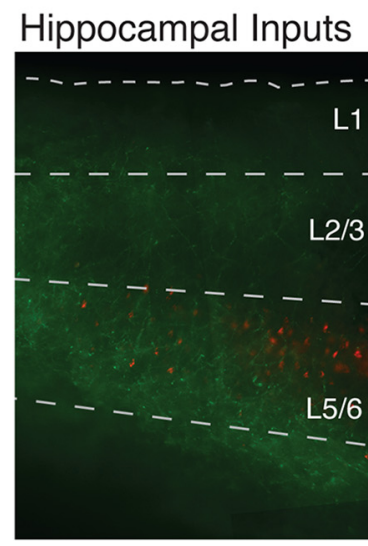

9 Commissural Inputs

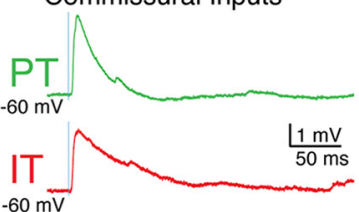

$\mathbf{h}_{\text {Hippocampal Inputs }}$

$\mathrm{PT}$

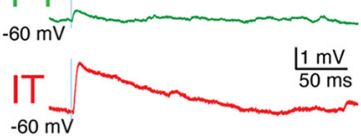

i $\square$ Nonresponsive

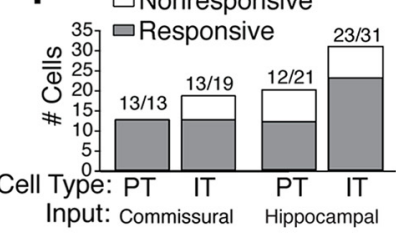

Figure 1. Optogenetic identification of commissural and hippocampal inputs to $L 5 \mathrm{mPFC}$ neurons. $\boldsymbol{a}, \boldsymbol{b}$, rAAV-encoding ChR2 was injected in the contralateral cortex ( $\boldsymbol{a}$ ) or the ipsilateral ventral hippocampus $(\boldsymbol{b})$. Retrograde fluorescent microspheres were injected in the pons to label PT neurons or in the contralateral cortex to label IT neurons (data not shown). c, $\boldsymbol{d}$, GFP expression in axons and terminals was evident at $4-12$ weeks post-infection. Filling $L 5$ pyramidal neurons with Alexa-594 $(20 \mu \mathrm{m})$ revealed dendritic morphology in relation to GFPlabeled axons and terminals. $\boldsymbol{e}$, Commissural axons and terminals (green) overlaid with Alexafilled dendrites (red) of an IT neuron. $f$, Hippocampal axons and terminals (green) overlaid with Alexa-filled dendrites (red) of a PT neuron. Scale bars, $100 \mu \mathrm{m} . \boldsymbol{g}-\boldsymbol{i}$, Physiological responses to optical activation. Light activation (1 ms, 0.2-2 mW, blue line) of commissural ( $\boldsymbol{g}$ ) and hippocampal (h) fibers elicited responses in PT (green) and IT (red) neurons. $\boldsymbol{i}$, Summary counts of the responses observed in the two L5 mPFC neuron types to commissural and hippocampal input. 
Table 1. Summary of the light-evoked responses elicited by hippocampal and commissural inputs to $L 5$ pyramidal neurons under different experimental conditions

\begin{tabular}{|c|c|c|c|c|c|c|c|c|}
\hline & \multicolumn{8}{|l|}{ Commissural inputs } \\
\hline & \multicolumn{2}{|l|}{ PT } & \multicolumn{2}{|l|}{ IT } & \multicolumn{2}{|l|}{ PT } & \multicolumn{2}{|l|}{ IT } \\
\hline & Soma & Dendrite & Soma & Dendrite & Soma & Dendrite & Soma & Dendrite \\
\hline \multicolumn{9}{|c|}{ Somatic monosynaptic responses, whole-field illumination } \\
\hline Amplitude & $\begin{array}{c}1.29 \pm 0.25 \mathrm{mV} \\
(n=7)\end{array}$ & - & $\begin{array}{c}1.02 \pm 0.17 \mathrm{mV} \\
(n=7)\end{array}$ & - & $\begin{array}{c}0.55 \pm 0.12 \mathrm{mV} \\
(n=5)\end{array}$ & - & $\begin{array}{c}1.01 \pm 0.12 \mathrm{mV} \\
(n=14)\end{array}$ & - \\
\hline Half-width & $\begin{array}{c}18.77 \pm 1.31 \mathrm{~ms} \\
(n=7)\end{array}$ & - & $\begin{array}{c}36.26 \pm 7.80 \mathrm{~ms} \\
(n=7)\end{array}$ & - & $\begin{array}{c}15.81 \pm 2.41 \mathrm{~ms} \\
(n=5)\end{array}$ & - & $\begin{array}{c}27.02 \pm 1.87 \mathrm{~ms} \\
(n=14)\end{array}$ & - \\
\hline \multicolumn{9}{|c|}{ Dual recordings, whole-field illumination } \\
\hline Amplitude & $\begin{array}{c}1.02 \pm 0.25 \mathrm{mV} \\
(n=15)\end{array}$ & $\begin{array}{c}3.35 \pm 0.66 \mathrm{mV} \\
(n=15)\end{array}$ & $\begin{array}{c}0.91 \pm 0.19 \mathrm{mV} \\
(n=7)\end{array}$ & $\begin{array}{c}1.65 \pm 0.27 \mathrm{mV} \\
(n=7)\end{array}$ & $\begin{array}{c}0.76 \pm 0.15 \mathrm{mV} \\
(n=11)\end{array}$ & $\begin{array}{c}1.28 \pm 0.29 \mathrm{mV} \\
(n=11)\end{array}$ & $\begin{array}{c}0.48 \pm 0.08 \mathrm{mV} \\
(n=5)\end{array}$ & $\begin{array}{c}1.78 \pm 0.48 \mathrm{mV} \\
(n=5)\end{array}$ \\
\hline Half-width & $\begin{array}{c}19.8 \pm 2.4 \mathrm{~ms} \\
(n=15)\end{array}$ & $\begin{array}{c}7.64 \pm 0.55 \mathrm{~ms} \\
(n=15)\end{array}$ & $\begin{array}{c}30.59 \pm 2.83 \mathrm{~ms} \\
(n=7)\end{array}$ & $\begin{array}{c}19.52 \pm 4.01 \mathrm{~ms} \\
(n=7)\end{array}$ & $\begin{array}{c}17.40 \pm 1.96 \mathrm{~ms} \\
(n=11)\end{array}$ & $\begin{array}{c}8.04 \pm 0.84 \mathrm{~ms} \\
(n=11)\end{array}$ & $\begin{array}{c}28.82 \pm 4.32 \mathrm{~ms} \\
(n=5)\end{array}$ & $\begin{array}{c}15.50 \pm 2.06 \mathrm{~ms} \\
(n=5)\end{array}$ \\
\hline \multicolumn{9}{|c|}{ Dual recordings, local illumination in TTX and 4-AP } \\
\hline Illumination at Tuft & $\begin{array}{c}0.29 \pm 0.13 \mathrm{mV} \\
(n=4)\end{array}$ & $\begin{array}{c}2.09 \pm 0.92 \mathrm{mV} \\
(n=4)\end{array}$ & $\begin{array}{c}0.33 \pm 0.04 \mathrm{mV} \\
(n=4)\end{array}$ & $\begin{array}{c}2.33 \pm 0.4 \mathrm{mV} \\
(n=4)\end{array}$ & $\begin{array}{l}4 \text { cells: } \\
0.05 \pm 0.11 \mathrm{mV} ; \\
1 \text { cell } 3 \text { trials: } \\
0.62 \pm 0.10 \mathrm{mV} \\
\quad(n=5)\end{array}$ & $\begin{array}{l}4 \text { cells: } \\
0.23 \pm 0.16 \mathrm{mV} \\
1 \text { cell, } 3 \text { trials: } \\
4.52 \pm 0.12 \mathrm{mV} \\
\quad(n=5)\end{array}$ & $\begin{array}{c}0.58 \pm 0.08 \mathrm{mV} \\
(n=3)\end{array}$ & $\begin{array}{c}1.99 \pm 0.6 \mathrm{mV} \\
(n=3)\end{array}$ \\
\hline Illumination at middle & $\begin{array}{c}0.15 \pm 0.09 \mathrm{mV} \\
\quad(n=4)\end{array}$ & $\begin{array}{l}0.056 \pm 0.11 \mathrm{mV} \\
\quad(n=4)\end{array}$ & $\begin{array}{c}0.16 \pm 0.09 \mathrm{mV} \\
(n=4)\end{array}$ & $\begin{array}{c}0.38 \pm 0.13 \mathrm{mV} \\
(n=4)\end{array}$ & $\begin{array}{l}4 \text { cells: } \\
0.21 \pm 0.02 \mathrm{mV} ; \\
1 \text { cell, } 3 \text { trials: } \\
0.08 \pm 0.08 \mathrm{mV} \\
\quad(n=5)\end{array}$ & $\begin{array}{l}4 \text { cells: } \\
0.12 \pm 0.04 \mathrm{mV} \\
1 \text { cell, } 3 \text { trials: } \\
0.17 \pm 0.23 \mathrm{mV} \\
\quad(n=5)\end{array}$ & $\begin{array}{l}0.13 \pm 0.09 \mathrm{mV} \\
\quad(n=3)\end{array}$ & $\begin{array}{c}0.24 \pm 0.08 \mathrm{mV} \\
(n=3)\end{array}$ \\
\hline Illumination at Soma & $\begin{array}{c}1.13 \pm 0.47 \mathrm{mV} \\
(n=4)\end{array}$ & $\begin{array}{c}0.23 \pm 0.14 \mathrm{mV} \\
(n=4)\end{array}$ & $\begin{array}{c}0.79 \pm 0.44 \mathrm{mV} \\
(n=4)\end{array}$ & $0.57 \pm 0.25 \mathrm{mV}$ & $\begin{array}{l}4 \text { cells: } \\
0.62 \pm 0.13 \mathrm{mV} ; \\
1 \text { cell, } 3 \text { trials: } \\
0.75 \pm 0.11 \mathrm{mV} \\
\quad(n=5)\end{array}$ & $\begin{array}{l}4 \text { cells: } \\
0.26 \pm 0.04 \mathrm{mV} \\
1 \text { cell, three trials: } \\
0.47 \pm 0.11 \mathrm{mV} \\
\quad(n=5)\end{array}$ & $\begin{array}{l}0.57 \pm 0.05 \mathrm{mV} \\
\quad(n=3)\end{array}$ & $\begin{array}{c}0.36 \pm 0.01 \mathrm{mV} \\
(n=3)\end{array}$ \\
\hline
\end{tabular}

$14.7 \pm 6.9 \%, n=3$; commissural to IT: $29.9 \pm 4.8 \%, n=7$; commissural to PT: $52.9 \pm 3.5 \%, n=6$ ).

Commissural input was monosynaptic in most IT (seven of nine) and PT (six of seven) neurons. Similarly, hippocampal input was monosynaptic in most IT neurons (13 of 15). In contrast, hippocampal input was monosynaptic in less than half of the PT neurons tested (five of 12). Thus, while hippocampal input can monosynaptically connect to PT neurons, this connection was less prevalent. Furthermore, commissural inputs elicited responses that were not significantly different between PT and IT neurons in amplitude, initial slope, and rise times (Table 1; Fig. $2 c$, right); however, hippocampal input to $\mathrm{PT}$ neurons was smaller in amplitude, initial slope, and rise time (PT, $n=5$; IT, $n=14$; $t$ test $p<0.05$; Table 1; Fig. $2 d$, right). Simultaneous recordings of PT and IT neurons within $70 \mu \mathrm{m}$ of each other confirmed that these differences were consistent across different slices (Fig. 2e). In six of six paired recordings, PT responses from hippocampal inputs were either absent, polysynaptic, or smaller than the observed response in the adjacent IT neuron. These data suggest that, measured at the soma, hippocampal inputs directly target IT neurons. Combined, these data suggested that hippocampal and commissural inputs entered the mPFC microcircuit very differently. Commissural inputs elicited robust direct responses in both IT and PT neurons, whereas hippocampal inputs elicited much stronger direct responses in IT than in PT neurons.

In addition to amplitude, we characterized the time course of elicited EPSPs by measuring their half-widths. For both afferent input types, half-widths were greater in IT neurons (Table 1; commissural PT, $n=7$; IT, $n=7$, $t$ test $p<0.05$; hippocampal PT, $n=5$; IT, $n=14$, $t$ test $p<0.05)$. Disparate somatic intrinsic properties of PT and IT neurons, due in part to hyperpolarization-activated cation current, $\mathrm{I}_{\mathrm{h}}$ (Dembrow et al., 2010), might partially account for the difference in EPSP halfwidth. To test this, we used dynamic clamp to inject an excitatory conductance at the soma in PT and IT neurons. Indeed, halfwidth evoked from simulated EPSCs (simEPSCs) were broader in IT neurons, but this did not fully account for the difference (PT: $13.60 \pm 0.75 \mathrm{~ms}, n=15$; IT: $17.11 \pm 1.46 \mathrm{~ms}, n=12$; $t$ test $p<$ $0.05)$. Because half-width is also particularly sensitive to dendritic filtering (Williams and Stuart, 2000; Berger et al., 2001), we performed dual dendritic-somatic recordings to specifically examine dendritic input.

\section{Dendritic integration of synaptic inputs to prefrontal neurons}

Voltage measurements of long-range inputs to pyramidal neurons have thus far been exclusively somatic (Petreanu et al., 2007; Anderson et al., 2010; Oviedo et al., 2010; Mao et al., 2011; Sheets et al., 2011; Lee et al., 2014). These measurements only represent a portion of the synaptic input, however, as filtering distorts the amplitude and time course of dendritic signals once they arrive at the soma (Magee and Cook, 2000; Williams and Stuart, 2002; Golding et al., 2005). Even under voltage-clamp conditions designed to minimize the effects of dendritic filtering, distortion of distal inputs is severe in L5 pyramidal neurons (Williams and Mitchell, 2008). To examine the dendritic input during longrange afferent fiber stimulation, we performed whole-field illumination while simultaneously recording from two zones of integration in these neurons: (1) the nexus at which the tuft of the apical dendritic arbor converges and (2) the soma.

Regardless of presynaptic input (commissural vs hippocampal) or postsynaptic target (PT vs IT), dendritic recordings re- 
a
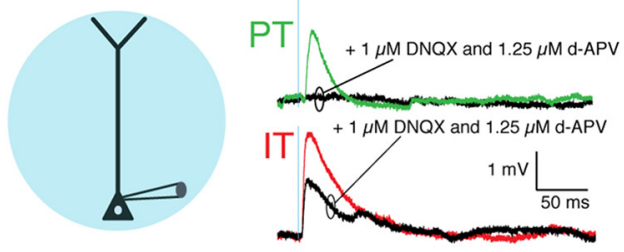

C

Commisural Inputs
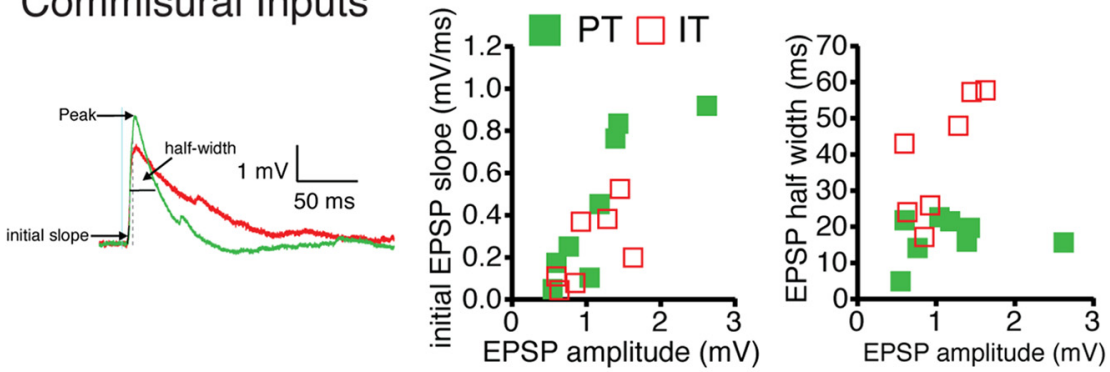

d
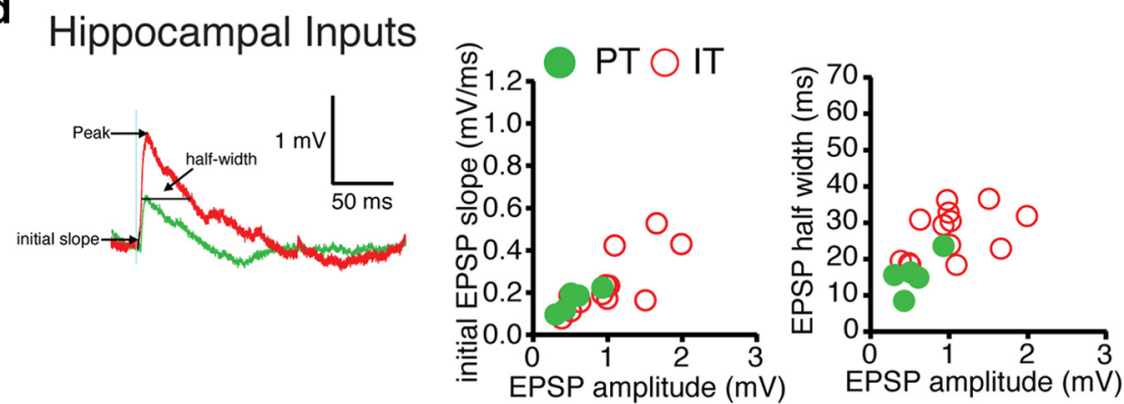

e
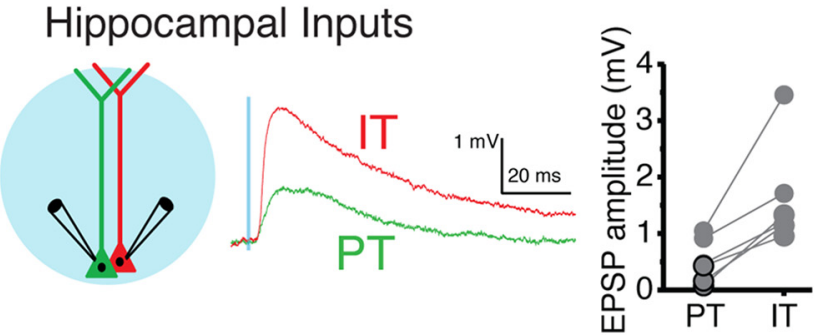

Figure 2. Monosynaptic ChR2-mediated responses in PT and IT neurons. $\boldsymbol{a}$, Even with minimal light stimulation, whole-field illumination (schematic, left), produced a mixture of polysynaptic and monosynaptic responses in PT (green) and IT (red) neurons. To minimize polysynaptic activation, a low concentration of excitatory synaptic blockers (black trace; $1 \mu \mathrm{m}$ DNQX and $1.25 \mu \mathrm{m}$ D-APV) was bath applied. Under these conditions, polysynaptic responses were blocked, while direct connections were only reduced in amplitude. $\boldsymbol{b}$, Summary counts of commissural and hippocampal inputs tested. Numbers indicate monosynaptic responses out of total. c, Illustration of parameters used to compare monosynaptic responses. As shown in the representative trace (right), commissural inputs elicited responses in PT (green, filled squares, $n=8$ ) with similar range of initial slope (middle) and peak amplitude as in IT (red, open squares, $n=7$ ), but longer half-widths (right). $\boldsymbol{d}$, Hippocampal inputs elicited smaller responses (middle) in PT neurons (green, filled circles, $n=5$ ), with shorter half-width (right) compared with IT neurons (red, open circles, $n=14)$.e, Simultaneous paired recordings (schematic and representative trace left, $n=6$ ) of PT and IT neurons ( $<70 \mu$ m apart) during stimulation of hippocampal inputs. Hippocampal inputs to PT neurons were consistently smaller in amplitude (middle) and initial slope (right).

vealed substantial dendritic responses that were not observable at the somatic recording electrode (Figs. 3-5). Dendritic responses $<1 \mathrm{mV}$ were barely detectable within noise at the somatic recording location $(\sim 200 \mu \mathrm{V})$. Whether the somatic electrode was in voltage-clamp or current-clamp mode, the somatic measurement is greatly attenuated (Fig. $3 a$ ). Indeed, the voltage escape at the dendritic electrode was similar whichever mode the somatic elec-

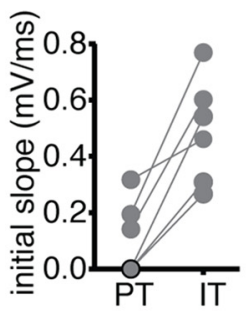

trode was in. To examine how well current was measured under whole-cell voltageclamp conditions, we used dynamic clamp to inject simulated synaptic currents at the dendrite (Fig. $3 b-d$ ). Injected dendritic currents with a peak $<100 \mathrm{pA}$ were not detectable at the soma. The inability of the somatic electrode to sufficiently clamp dendritic events was emphasized by the significant voltage escape in the dendrites (Fig. 3d). Thus, even under whole-cell voltage-clamp conditions, the intrinsic properties of dendritic compartments substantially distorted recorded events at the soma.

Responses to commissural input were larger at the dendrite in all PT (15 of 15) and most IT (six of seven) neurons (Fig. $4 a, c)$. The dendritic EPSP amplitude was $4.08 \pm 0.60$ times greater in PT neurons (paired $t$ test, $p<0.05, n=15$ ) and $2.12 \pm$ 0.35 times greater in IT neurons (paired $t$ test, $p<0.05, n=7$ ). Similarly, responses to hippocampal input were larger in the dendrites in most PT (eight of 12) and IT (four of five) neurons (Fig. $4 b, d$ ). Dendritic inputs were $2.51 \pm 0.61$ times greater in PT neurons (paired $t$ test, $p<$ $0.05, n=12$ ) and $3.47 \pm 0.54$ times greater in IT neurons (paired $t$ test, $p<$ $0.05, n=5$ ). For both input types and postsynaptic target, the dendritic EPSP half-widths were smaller than somatic EPSPs (Table 1; Fig. 4f,g).

Clearly, dendritic responses were larger (and briefer) than somatic ones in both neuron types. How did PT and IT dendritic responses compare to each other? This depended on input type. Commissural inputs elicited significantly larger EPSPs in PT dendrites (Table 1; PT, $n=15$; IT, $n=7$; $t$ test, $p<0.05)$. Hippocampal inputs elicited dendritic EPSPs that were not significantly different between the neuron types (Table $1 ; \mathrm{PT}, n=$ 11; IT, $n=5 ;$ test, $p=0.11)$. Regardless of the input, half-widths of dendritic EPSPs were significantly less in PT than in IT neurons (Fig. $4 f, g ; F_{(34,1)}=31.138, p<$ $0.01)$. These data were consistent with faster functional membrane time constants in the dendrites of both PT and IT neurons (Kalmbach et al., 2013).

To test whether responses we measured at the nexus of the dendritic tuft could trigger a dendritic action potential, we depolarized the dendritic recording location by $5-15 \mathrm{mV}$ while stimulating commissural fibers. In PT neurons, this reliably triggered a dendritic action potential, followed by a somatic action potential (four of five neurons; Fig. 4e). For IT neurons, commissural input could trigger a dendritic action potential (one of four neurons), but this depolarization was either insufficient to trigger an action potential (two of four neurons) or a somatic 
action potential preceded the dendritic action potential (one of four neurons). These results suggest that for PT neurons, a prominent integration zone for action potential initiation exists in the distal dendrites, which may be capable of recruiting axonal output.

Wide-field activation of hippocampal and commissural fibers elicited substantial dendritic responses in both PT and IT neurons. These dendritic responses were complicated by two factors. First, polysynaptic activity was intact and, as such, feedforward excitation could target the dendrites of PT and IT neurons. Second, stimulating a wide field might activate axons that synapse onto subcellular compartments outside the field of activation. To compare the monosynaptic somatic versus dendritic input required more selective stimulation. To do this, we blocked axonal propagation pharmacologically (1 $\mu \mathrm{M}$ TTX, $100 \mu \mathrm{M} 4$-AP) and reduced the field of illumination to allow selective activation of terminals over the apical dendritic tuft, the perisomatic region (including the basal dendrites), and the portion of apical dendrite between them (Fig. 5). Responses persisted with axonal propagation blocked (commissural: three of four IT and four of four PT neurons; hippocampal: five of seven IT and five of 10 PT neurons); further confirming that commissural and hippocampal fibers provide monosynaptic connections to both neuron types.

Activating commissural terminals over the tuft elicited responses in both PT and IT neurons at the dendritic recording location (Table 1; Fig. 5a,b). These responses were attenuated in amplitude at the soma (PT: $14.32 \pm 0.39 \%$; IT: $15.32 \pm$ $0.31 \%$ of the original signal). Conversely, commissural terminals over the soma elicited somatic responses (Table 1), which were attenuated in amplitude at the dendritic electrode (Fig. 5a,b; PT: $13.64 \pm$ $0.82 \%$; IT: $59.80 \pm 15.24 \%$ of the original signal). Local dendritic responses were larger than local somatic responses in both neuron types, but this was only significant in IT neurons (IT: ANOVA with repeated measures, $F_{(2,4)}=25.49, p<$ 0.01 , post hoc comparisons, $p<0.05$; PT: $F_{(2,6)}=12.63, p<0.01$, post hoc comparison, $p>0.1$ ). This was in contrast to our dual recordings without axonal propagation intact (Fig. 4), suggesting that significant feedforward excitation targets the dendrites of PT neurons. For both neuron types, illuminating between the two electrodes elicited no response at either the somatic or dendritic recording location (Fig. 5a,b). As this response was smaller than the propagated responses from more distal locations, our data suggested that commissural inputs to the middle region were relatively weak. Thus commissural inputs converge onto both dendritic and perisomatic compartments, and in the case of IT neurons the dendritic input was significantly larger.

a circles) neurons.

\section{ChR2-evoked Responses}

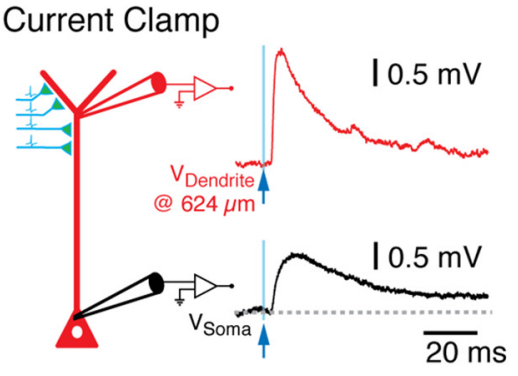

Voltage Clamp

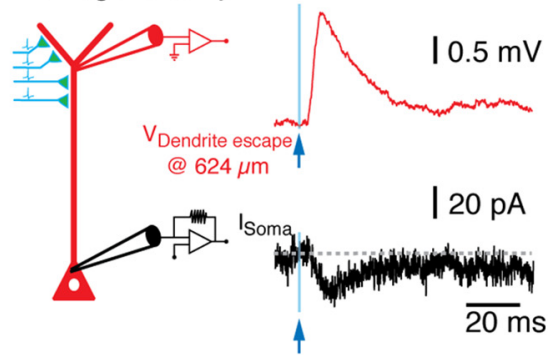

\section{Simulated EPSCs injected in Dendrite}
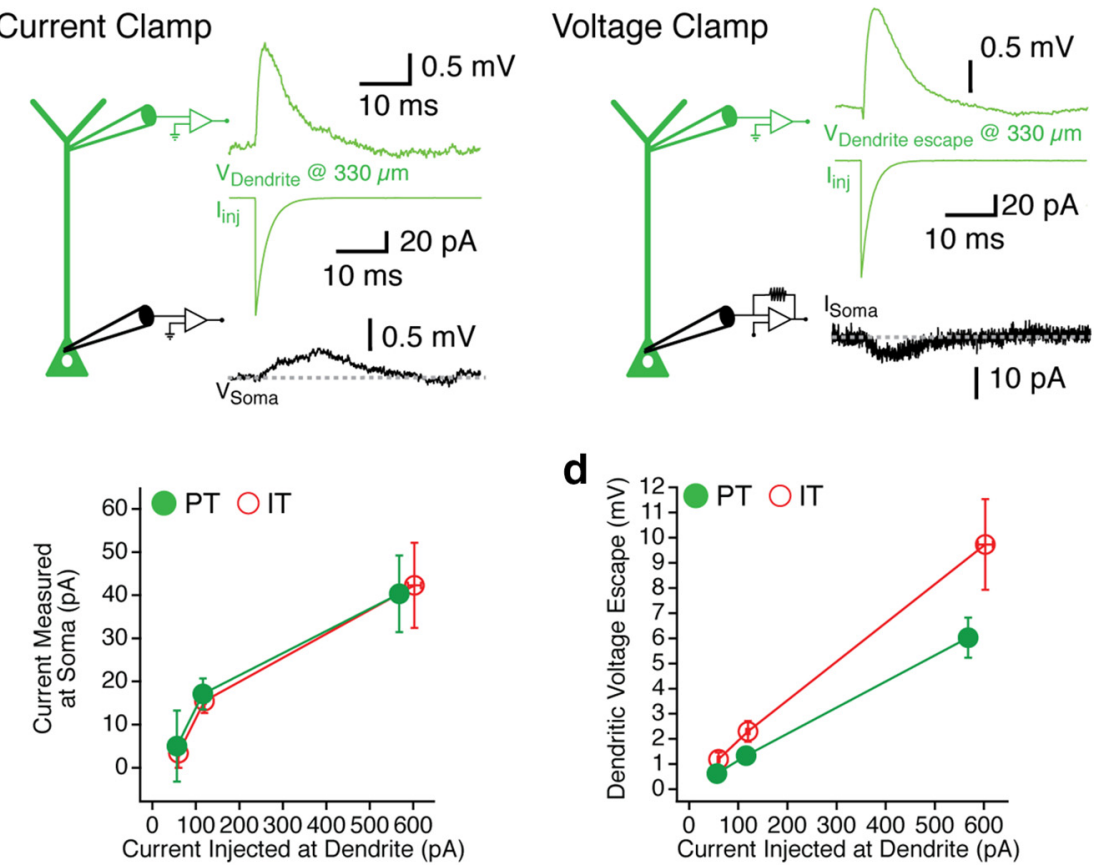

Figure 3. Somatic voltage clamp does not accurately reflect dendritic responses. $\boldsymbol{a}$, Responses in an IT (red) neuron to stimulation of commissural input ( $1 \mathrm{~ms}$, blue line with arrow). Responses were measured at the soma and dendrite ( $624 \mu \mathrm{m}$ from soma) somatic electrode. $\boldsymbol{b}$, A point conductance injected at the dendritic electrode ( $2 \mathrm{nS}, 330$ um away from the soma) in a PT neuron was greatly attenuated at the soma in both current clamp (left) and voltage clamp (right). $\boldsymbol{c}, \boldsymbol{d}$, The peak somatic current measured at fied across a range of simulated synaptic currents injected at the dendrites for PT ( $n=3$, green filled circles) and IT ( $n=3$, red open than commissural inputs, depending upon the neuron type. Activating hippocampal terminals over the tuft elicited a dendritic EPSP in IT neurons (Table 1) that was attenuated at the somatic electrode (Fig. $5 c ; 36 \pm 9 \%$ of the original signal). Only one of five PT neurons responded to activation of hippocampal terminals at the dendrite while the remaining four of five did not (Table 1). Activating perisomatic hippocampal terminals elicited a somatic EPSP in both PT and IT neurons (Table 1) that was attenuated at the dendritic electrode (PT: $64.8 \pm 8 \%$; IT: $36 \pm 9 \%$ of the original signal). As was the case for commissural fibers, local responses to hippocampal input were significantly larger in IT dendrites than the IT soma (ANOVA with repeated measures, $F_{(2,6)}=5.122, p<0.05$, post hoc comparisons, $\left.p<0.05\right)$. Similar to commissural inputs, no responses were detected from illumi- 
a

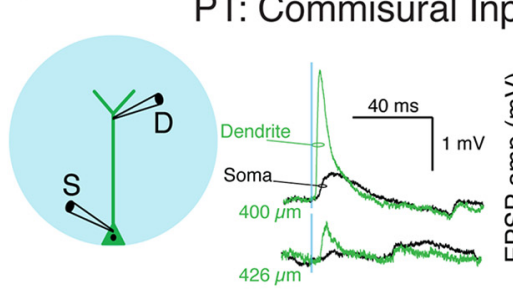

PT: Commisural Inputs

C

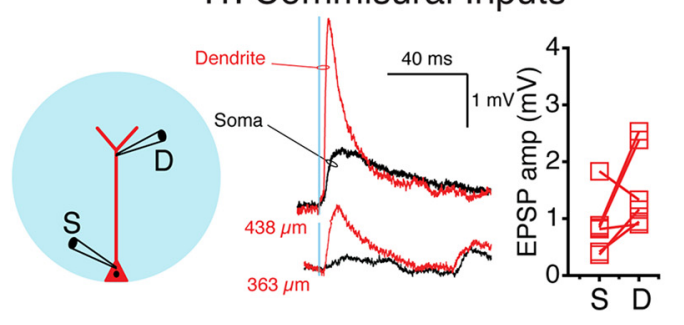

b

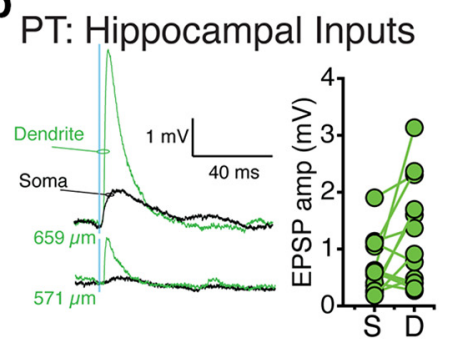

d

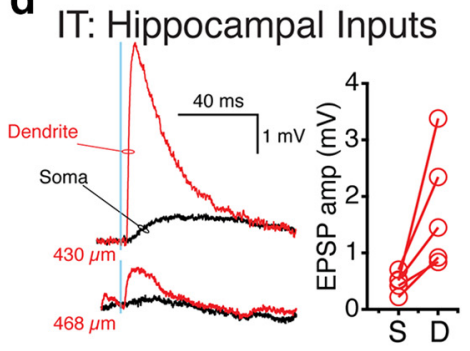

e

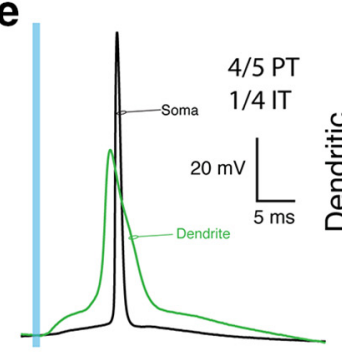

f Commisural Inputs

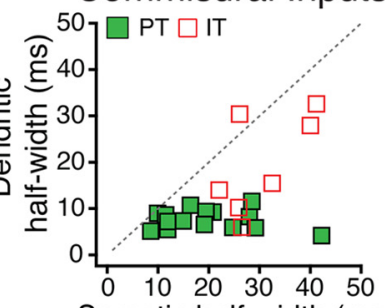

Somatic half-width $(\mathrm{ms})$

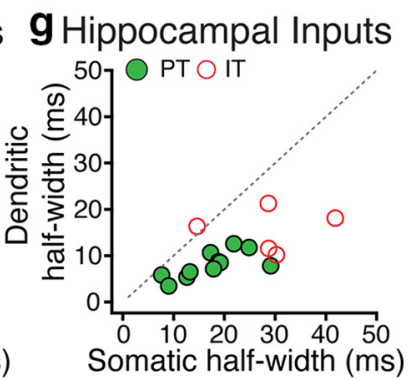

Figure 4. Dendritic inputs to PT and IT neurons. $\boldsymbol{a}-\boldsymbol{d}$, Simultaneous dual recordings from the apical dendrite (D, colored) and the soma (S, black) were performed while activating either commissural ( $\boldsymbol{a}$, $\boldsymbol{c}$, squares; $\mathrm{PT}, n=15 ; \mathrm{IT}, n=7$ ) or hippocampal ( $\boldsymbol{b}$, $\boldsymbol{d}$, circles; PT, $n=12 ; \mathrm{IT}, n=5)$ fibers. For both PT neurons $(\boldsymbol{a}, \boldsymbol{b}$, green) and IT neurons $(\boldsymbol{c}, \boldsymbol{d}$, red) two representative traces are shown for each condition, one where the dendritic response was large enough $(>1 \mathrm{mV})$ to be observed at the somatic electrode, and one that was not. Distances of the recording site are listed under each representative trace. Average responses for each neuron at the soma (S) and the dendrite (D) are shown for each condition. $\boldsymbol{e}$, Commissural fiber activation (1 ms, blue line) can trigger a dendritic action potential (green) preceding a somatic action potential (black) in four of five PT and one of five IT neurons. $\boldsymbol{f}, \boldsymbol{g}$, For both commissural $(\boldsymbol{f})$ and hippocampal $(\boldsymbol{g})$ inputs, the somatic EPSP half-width is much greater than the dendritic EPSP half-width for both PT (green, filled symbols) and IT (red, open symbols) neurons.

nating between the recording locations for either neuron type. Combined, these data suggest that PT and IT neurons integrate long-range afferent input at two electrically distant locations: the nexus of the apical dendrite and the soma.

\section{Frequency dependence of dendritic filtering in PT and IT neurons}

For both PT and IT neurons, long-range afferent fibers elicited distinct synaptic input at the dendrite and soma. These locations were electrotonically distant and therefore dendritic filtering could play an important role in how they interact. To test how time-varying signals were filtered in amplitude depending upon their frequency, we calculated impedance amplitude profiles (ZAPs) by injecting sinusoidal current over a range of frequencies. PT and IT neurons exhibited different filter characteristics, depending on the signal's temporal properties. IT neurons function as low-pass filters, attenuating fast signals such that slow signals $(<2 \mathrm{~Hz})$ were preferentially amplified. PT neurons function as bandpass filters, attenuating both slow $(<2 \mathrm{~Hz})$ and fast $(>7 \mathrm{~Hz})$ signals, such that a frequency band $(3-6 \mathrm{~Hz})$ was amplified. As we have shown previously, differences in the dendritic ZAP were substantial between PT versus IT dendrites (Fig. $6 b, c$; Kalmbach et al., 2013). To test how time-varying signals were transferred from dendrite to the soma, we calculated the transferred ZAP from the somatic voltage response to dendritic current injection (Fig. $6 b-d$ ). The peak transfer frequency from dendrite to soma was $5.82 \pm 0.17 \mathrm{~Hz}$ for PT neurons $(n=51)$ and $1.09 \pm 0.42 \mathrm{~Hz}$ for IT neurons $(n=19)$. Notably, signals with higherfrequency components $(>7 \mathrm{~Hz})$ were filtered similarly as they passed from dendrite to soma in the two neuron types. Thus, differences in the amplitude attenuation of voltage signals depended greatly on which frequency components it contained. Differences in the ZAPs of PT and IT neurons were likely due to differences in the $\mathrm{h}$ current (Dembrow et al., 2010). The distinct filtering properties of $\mathrm{PT}$ and IT neurons were further accentuated in the apicaldendrite wherehyperpolarizationactivated cyclic-nucleotide gated ion channels (h channels) are enriched (Williams and Stuart, 2000; Berger et al., 2001; Kalmbach et al., 2013). To test whether $h$ channels were necessary for the bandpass characteristics observed in PT neurons, we bath applied the h-channel blocker 4 ZD7288 (20 $\mu \mathrm{M}, n=5)$. In ZD7288, dendritic resonance frequency was reduced from $6.35 \pm 1.37$ to $1.29 \pm 0.24 \mathrm{~Hz}$ (paired $t$ test, $p<0.05, n=5$ ) and transfer frequency was reduced from $4.69 \pm 0.83$ to $1.06 \pm 0.02 \mathrm{~Hz}$ (Fig. $6 j$, paired $t$ test, $p<$ $0.05, n=5)$.

In addition to being attenuated in amplitude in a frequency-dependent manner, signals were also altered in phase. To quantify this, we calculated the local and transferred impedance phase profiles (ZPPs). In hippocampal pyramidal dendrites, slow-frequency signals are phase advanced relative to the current driving them, while faster frequency signals lag in phase. This is the result of the phenomenological inductance caused by the high density of h channels in the dendrites (Narayanan and Johnston, 2008; Vaidya and Johnston, 2013). We observed this phase advancement in the dendrites of PT but not IT neurons (Fig. 6f,g). The local somatic ZPP was not phase advanced at any frequency in either neuron type. As has been reported in hippocampal pyramidal neurons, the transferred ZPP (dendrite to soma) was phase advanced relative to the somatic ZPP at lower frequencies, then phase delayed at higher frequencies (Fig. 6h). At the particular frequency at which these two plots intersect, the local somatic signal and the transferred dendritic signal were synchronized. This synchronization frequency was $6.63 \pm 0.21 \mathrm{~Hz}$ $(n=51)$ for PT neurons. Most IT neurons did not exhibit synchronization frequency within the detection range of our analysis (four of 19 neurons, $1.55 \pm 0.16 \mathrm{~Hz} ; 15$ of 19 neurons, no synchronization frequency $>1 \mathrm{~Hz}$ ). These data suggest that unlike PT neurons, input to the IT dendrites will always be phase delayed relative to somatic input. Synchronization frequency in PT neurons was dependent upon h channels. Blocking h channels with ZD7288 $(20 \mu \mathrm{M})$ made dendritic signals always lag so- 
a
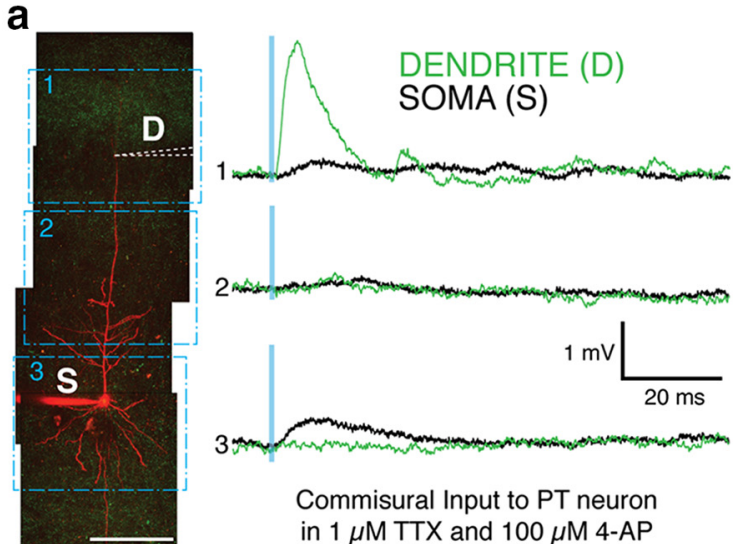

Commisural Input to PT neuron in $1 \mu \mathrm{M}$ TTX and $100 \mu \mathrm{M} 4-\mathrm{AP}$

\section{b Commisural Inputs}

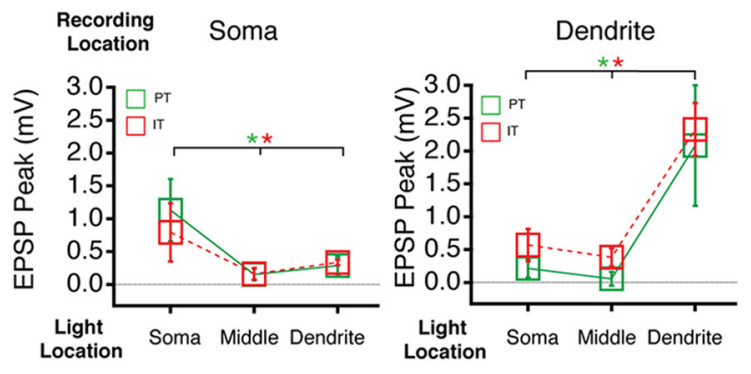

C Hippocampal Inputs

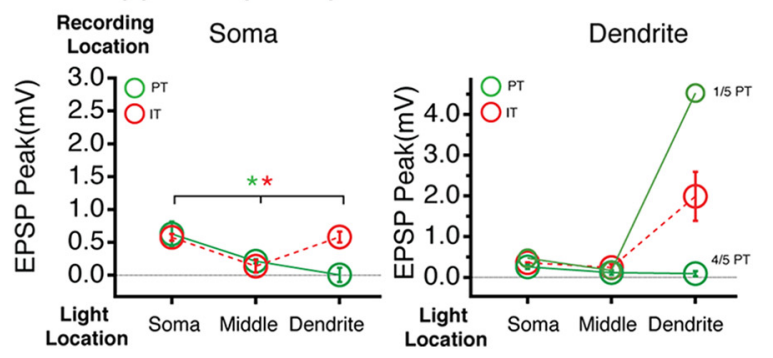

Figure 5. Activation of hippocampal and commissural terminals synapsing onto PT and IT neurons. $\boldsymbol{a}$, Dual recording from a PT neuron from the soma $(S)$ and the nexus of the apical dendrite (D, $587 \mu \mathrm{m}$ from soma). With action potential propagation blocked pharmacologically (1 $\mu \mathrm{M}$ TTX, $100 \mu \mathrm{M} 4$-AP), commissural fibers were activated using a limited field of illumination ( $260 \times 390 \mu \mathrm{m}$, blue square) over the apical tuft (1), in between the two electrodes (2), or over the soma (3) while measuring responses at the dendrite (green) and soma (black). Average responses for commissural ( $\boldsymbol{b}$, squares; PT, $n=4 ; \mathrm{IT}, n=3$ ) and hippocampal ( $\boldsymbol{c}$, circles; PT, $n=5 ; \mathrm{IT}, n=4$ ) at the soma (left) and the dendrite (right) recording locations while activating terminals at the soma, in between the two electrodes, and over the apical tuft (dendrite). PT neurons are shown with green open symbols connected with solid lines. IT neurons are shown with red open symbols connected with dashed lines.

matic ones, effectively eliminating any synchronization frequency (Fig. $6 k$ ).

Depending on the frequency components of dendritic input, PT and IT neurons integrated signals at the soma quite differently. To test how more realistic time-varying signals were integrated, we used dynamic clamp to inject a point conductance $(2-10 \mathrm{nS})$ that mimicked the synaptic response we observed using ChR2 stimulation. We injected these simEPSCs at the dendrite while simultaneously recording the voltage response from the soma (Fig. 7). In the absence of precise information regarding the kinetics and amplitude of a synaptic conductance in PT and IT neurons elicited from hippocampal and/or commissural input, we used a range of conductance amplitudes and chose a current decay that approximated our dendritic ChR2-evoked responses in PT and IT neurons (decay time constant, $2 \mathrm{~ms}$ ).

Across a range of conductances, a single EPSP attenuated in amplitude from the dendrite to soma similarly in both neuron types (Fig. $7 b$ ). The magnitude of the amplitude attenuation depended upon the distance between the dendritic and somatic recording location (Fig. 7c). The slope of the distancedependence increase in attenuation was not significantly different between PT and IT neurons (ANCOVA, $F_{(1,30)}=0.017, p=$ 0.897). Thus, our data indicate that for single EPSPs, amplitude attenuation was not different between IT and PT neurons. To assess why this was the case, we analyzed the frequency components of the injected simEPSC signals using a CWT (for $10 \mathrm{nS}$; Fig. 8a). As expected, simEPSCs in PT and IT neurons were composed of identical frequency components. The strongest frequency component of a simEPSC peaked at $\sim 88 \mathrm{~Hz}$, with weaker power at the lower frequencies. Thus a single simEPSC comprised primarily frequency components above the range where PT and IT dendrites had different filtering properties $(>15 \mathrm{~Hz}$; Fig. $6 d$ ). These data were consistent with small differences between the peak amplitudes of transferred EPSPs of PT and IT neurons.

While the amplitude of transferred EPSPs attenuated similarly, the time courses of the transferred EPSPs for PT and IT neurons were very different. The half-width of transferred EPSPs was significantly greater in IT neurons (PT: $18.39 \pm 0.83 \mathrm{~ms}, n=$ 13; IT: $38.51 \pm 2.36 \mathrm{~ms}, n=12$; Student's $t$ test, $p<0.05)$. The delay to the peak of EPSPs traveling to the soma was also longer in IT neurons (Fig. 7e). These data were consistent with our sinusoid current injections, which indicated that unlike transferred ZAPs, transfer ZPPs of PT and IT neurons do not overlap at higher frequencies. To examine how PT and IT neurons integrate inputs at different distances, we compared the delay to peak of a transferred EPSP to the delay to peak of a local (somatic) EPSP. In PT neurons, the delay of the transferred EPSPs did not change significantly with increasing distances (ANCOVA, $F_{(1,17)}=$ $2.913, p=0.106)$. In contrast, the delay in peak of the transferred EPSP increased with distance in IT neurons (ANCOVA, $F_{(1,12)}=$ $9.959, p<0.01$ ). We conclude that while the amplitude attenuation of simEPSCs was equivalent for IT and PT neurons, the temporal distortion was much more severe in IT neurons. To test whether the temporal normalization of dendritic inputs in PT neurons were caused by h channels, we tested the delays in transferred EPSPs in the presence of ZD7288 (20 $\mu \mathrm{M} ; n=5)$. In ZD7288, there was a striking distant-dependent increase in the delay of dendritic inputs (Fig. 7e). Thus, the temporal normalization along the apical dendrite in PT neurons depends upon h currents.

Recordings of both simEPSCs and ChR2-evoked EPSPs indicated that, for a single EPSP, the primary effect of the unique filtering properties of PT and IT dendrites was upon the time course and not the peak of synaptic events. As such, trains of synaptic input might be filtered differently between PT and IT neurons. To test this, we triggered five simEPSCs in the dendrites across a range of frequencies $(20-200 \mathrm{~Hz})$ and examined how they transferred to the soma (Fig. 7e). Within a select burst range $(40-140 \mathrm{~Hz})$, transferred EPSPs summated (fifth peak/first peak) more in IT neurons compared with PT neurons. To test what burst frequencies were dependent upon h channels in PT neurons, we bath applied ZD7288 $(20 \mu \mathrm{M})$. We found that at all burst frequencies tested, ZD7288 enhanced the summation of EPSPs at the soma (Fig. 7i; ANOVA with repeated measures, $F_{(9,36)}=$ $411.2, p<0.01$, post hoc comparisons, $p<0.01$ ). Thus, as expected, h-channel blockade greatly enhanced temporal summa- 
a

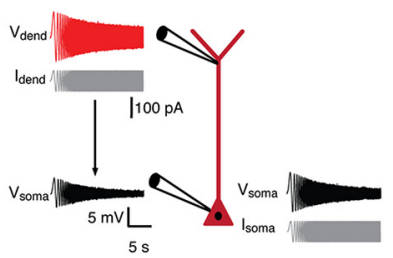

d
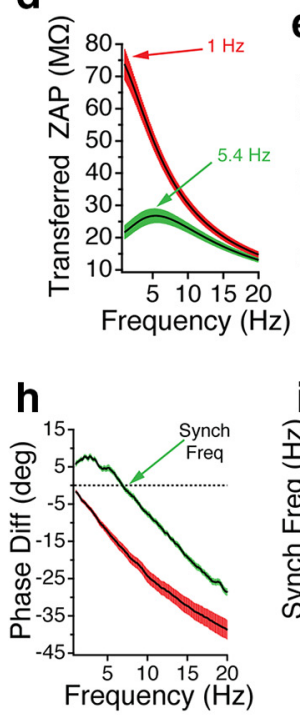

Figure 6. Dendritic filtering properties of PT and IT neurons. $\boldsymbol{a}-\boldsymbol{h}$, Injecting chirp stimuli $(\boldsymbol{a})$ at the dendrite or soma provides ZAPs $(\boldsymbol{b}-\boldsymbol{d})$ and ZPPs $(\boldsymbol{f}-\boldsymbol{h}) \cdot \boldsymbol{b}$, Dendritic (green), somatic (black), and dendrite-to-soma-transferred (green dashed) ZAPs in a PT neuron. $\boldsymbol{c}$, Dendritic (red), somatic (black), and dendrite-to-soma-transferred (red dashed) ZAPs in an IT neuron. $\boldsymbol{d}$, Comparing averaged transferred ZAPs of IT $(n=18)$ and PT $(n=23)$ neurons, with peak transfer frequency indicated. $\boldsymbol{e}$, Peak transfer frequencies of PT (solid green) and IT (open red) neurons as a function of recording distance. $f$, Dendritic (green), somatic (black), and dendrite-to-soma-transferred (green dashes) ZPPs in a PT neuron. $\boldsymbol{g}$, Dendritic (red), somatic (black), and dendrite-to-somatransferred (red dashes) ZPPs in an IT neuron. $\boldsymbol{h}$, Phase difference between the dendrite and soma (dendrite-soma) of IT and PT neurons, with the synchronization frequency (Synch Freq) of the PT neuron indicated. $i$, Synch Freq in PT (solid green) and IT (open red) neurons as a function of the distance of recording. In cases where the transferred dendritic ZPP never led the soma, a zero is indicated. $\boldsymbol{j}, \boldsymbol{k}$, PT neurons' (solid green) Synch Freq eliminated $(\boldsymbol{j})$ and transfer frequency $(\boldsymbol{k})$ is reduced to $1 \mathrm{~Hz}$ by addition of the h-current blocker (ZD7288, $20 \mu \mathrm{m}$, open black circles).

tion in PT neurons. Analyzing the frequency components of simEPSCs using CWT revealed that simEPSC bursts also possess slower frequency components (Fig. $8 d-j$ ). The peak frequency of this slow component spans frequency ranges over which PT and IT ZAPs differed significantly. To examine whether this might account for differences in the summation of transferred bursts, we compared the transfer impedance of PT versus IT neurons at the peak of the slow component for each burst (normalizing for its relative power). Matching our summation data, we found that in the gamma frequency range $(40-120 \mathrm{~Hz})$, the efficiency of signal transfer to the soma was much greater in IT neurons (Fig. $8 f, i)$. The frequency components of the somatic voltage waveform revealed the temporal distortion of bursts in PT versus IT neurons. In PT neurons, the voltage signals comprised a slow peak frequency component $(2-10 \mathrm{~Hz})$ that increased depending upon the input burst frequency (Fig. 8j). In contrast, the voltage waveform in IT neurons across a wide range of burst input frequencies $(100-200 \mathrm{~Hz})$ exhibited the same peak frequency $(4.16 \pm 0.12 \mathrm{~Hz}, n=54$; Fig. $8 j$ ) with equivalent power (Fig. $8 k$ ). These data suggest that while PT somatic voltage waveforms reflect the burst frequency of dendritic input, IT somatic voltage waveforms do not.

The temporal distortion of dendritic inputs traveling to the soma suggested that IT neurons would integrate spatially distrib-

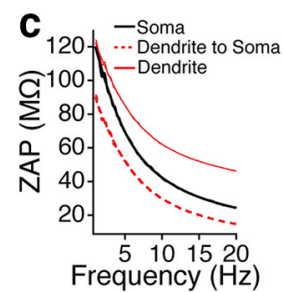

uted synaptic input over a wider temporal window. To test how L5 somata integrated input from two different locations [(1) the nexus of the apical dendrite; (2) the soma], we triggered dendritic and somatic simEPSCs at intervals spanning from -50 to $+90 \mathrm{~ms}(\Delta 10 \mathrm{~ms}$ steps; Fig. $7 f$ ). Dendritic and somatic simEPSCs triggered simultaneously made the somatic simulated EPSP significantly larger (Fig. $7 g$; PT: $t=4.9008, \mathrm{df}=11, p<0.01$; IT: $t=4.5063, \mathrm{df}=5, p<0.05)$. Spatial summation was greater in IT neurons than in PT neurons and occurred over a wider temporal window (Fig. $7 f$ ). The magnitude of summation in IT neurons was distance dependent: more distal dendritic EPSPs correlated with weaker summation $\left(r^{2}=0.8628, p<0.01\right)$. In PT neurons, there was no significant correlation between summation and the distance of the dendritic current injection $\left(r^{2}=0.0178\right.$, $p=0.6792$ ). While PT and IT neurons both summated inputs along their dendrite at the soma, the magnitude of the summation depended upon different factors. IT neurons appeared more sensitive to the spatial distribution of synaptic inputs, whereas PT neurons were more sensitive to the temporal distribution of synaptic inputs.

\section{Discussion}

In this study we characterized how longrange synaptic inputs were integrated by the dendrites of PFC L5 projection neurons. PT and IT neurons received monosynaptic input from the hippocampus and contralateral PFC. Depending upon the input pathway and postsynaptic target, different subcompartments were targeted. In addition, PT and IT neurons filtered dendritic input differently: IT neurons integrated spatially distributed inputs with temporal distortion, while PT neurons were most responsive to spatially distributed synaptic inputs within a narrow time window. Thus, afferent inputs from contralateral cortex and the hippocampus communicate to $\mathrm{mPFC}$ differently by selectively targeting L5 mPFC neurons with distinct dendritic filtering properties.

\section{Afferent input to the dendrites of L5 mPFC neurons}

Optogenetic activation has previously been used to map synaptic inputs of afferent projections to sensory, motor, and prefrontal cortex (Petreanu et al., 2007; Anderson et al., 2010; Oviedo et al., 2010; Mao et al., 2011). For most neuron types examined, activating terminals over the apical dendrite while recording at the soma provides the impression that the synaptic input to the dendrite of L5 pyramidal neurons is relatively weak, while the strongest physiological response is produced from activating perisomatic terminals. However, these maps are derived from somatic measurements and cannot account for the substantial dendritic filtering of distal inputs. Our study is the first that we are aware of to directly examine the electrophysiological response in the dendrites to select long-range afferent inputs. In contrast to previous 

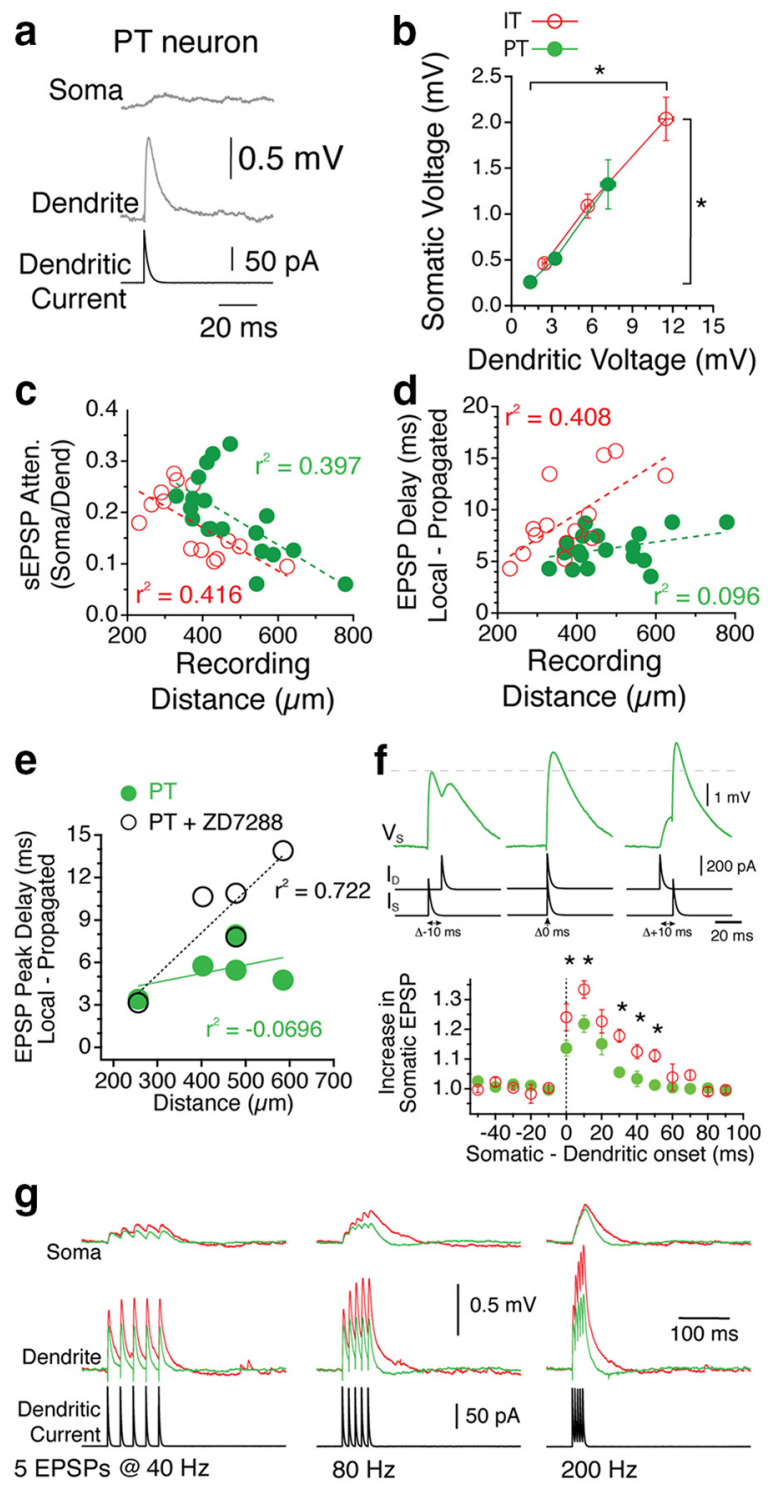

h
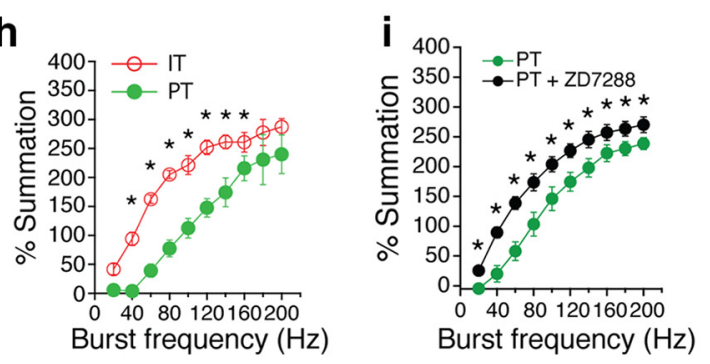

Figure 7. Dendritic filtering of simulated EPSPs. While performing dual somatic dendritic recording, point conductance was injected at the dendritic electrode using dynamic clamp and measured both at the dendrite and at the soma. $\boldsymbol{a}$, Representative trace of a $1 \mathrm{nS}$ conductance at the dendrite of a PT neuron. $\boldsymbol{b}$, With increasing synaptic conductance $(2,5$, and $10 \mathrm{nS}$ with a $2 \mathrm{~ms}$ decay time constant), synaptic currents resulted in larger dendritic EPSPs in IT neurons (open red symbols) compared with PT neurons (filled green symbols), but EPSP peaks attenuated similarly from dendrite to soma across a range of synaptic conductances. C, EPSPs exhibited similar distance-dependent attenuation between PT and IT neurons. $\boldsymbol{d}$, Temporal distortion of EPSPs (delay in the time to peak of the transferred EPSP, in milliseconds) exhibited greater distance dependence in IT neurons compared with PT neurons. $\boldsymbol{e}$, The distant-dependent normalization in PT neurons (filled green circles) was reduced by bath application of the ZD7288 (20 $\mu \mathrm{M}$, open black circles). $\boldsymbol{f}$, Somatic summation of coincident dendritic and somatic simEPSCS depends upon their relative timing. Top, Representative example of somatic summation of dendritic and somatic input for a PT neuron. Somatic $\left(I_{S}\right)$ and dendritic $\left(I_{D}\right)$ simEPSCS were triggered at different intervals (left: $-10 \mathrm{~ms}$, soma preceding dendrite; middle: indirect measurements, we have discovered that the dendrites of L5 mPFC neurons receive significant synaptic input from longrange afferent fibers. Direct recordings from the nexus at which the apical tuft converges reveal significant dendritic depolarization $(0.5-11 \mathrm{mV})$. Both light-evoked EPSPs and simulated synaptic EPSPs attenuate in amplitude greatly upon reaching the soma (ChR2-evoked: $\leq 9$-fold reduction; simulated synaptic currents: $\leq 16$-fold reduction). Measured at the somatic electrode, responses from activation of terminals over the apical tuft were smaller than those from perisomatic terminals. This is due to dendritic filtering: upon reaching the soma, dendritic responses attenuated to $\sim 15 \%$ of their original size. While not as strong as the attenuation observed in spontaneous EPSPs in L5B neurons of somatosensory cortex ( $\sim 40$-fold reduction), the attenuation in PFC neurons was sufficient to effectively segregate small dendritic voltage fluctuations from the soma (Berger et al., 2001; Williams and Stuart, 2002).

Responses reported here are likely to underestimate the synaptic inputs. Voltage signals attenuate strongly from the tuft dendrites to the nexus in somatosensory L5 neurons (Berger et al., 2001; Williams and Stuart, 2002; Harnett et al., 2013), so it is likely that our recordings at the nexus are attenuated signals of synaptic input. Similarly, synaptic input onto the basal dendrites can be attenuated substantially ( $>30$-fold) in somatosensory neurons (Nevian et al., 2007), and thus is likely to be underestimated by our somatic recordings.

What are the functional consequences of local depolarization in the apical dendrites? While single, local depolarizing events themselves may not reach the soma; they nonetheless contribute to the computing power of a neuron. Indeed, we found that with sufficient depolarization, dendritic input can drive a dendritic action potential in PT neurons that is distinct from (and can propagate to) the soma (Fig. 4e). As such, PT neurons have two distinct zones of integration: the nexus and the soma.

Even without directly triggering a dendritic action potential, dendritic depolarization can alter action potential output and local synaptic plasticity (Larkum et al., 2004; Golding et al., 2002). Dendritic EPSPs can alter the height of backpropagating action potentials by inactivating $\mathrm{K}^{+}$channels (Watanabe et al., 2002). Dendritic depolarization coupled with backpropagating action potentials has been shown to trigger tuft-wide regenerative events that produce bursts of action potentials (Larkum et al., 1999a,b; Barth et al., 2008; Harnett et al., 2013). Such coordination between different neuronal compartments has been proposed as an associative mechanism at the single-neuron level (Larkum, 2013). Our data suggest that associative computational mechanisms also could occur in PFC neurons, but that while commissural input may more readily recruit such associative mechanisms on its own, hippocampal input would require coincident input from other synaptic sources.

$\leftarrow$

simultaneous; right: $+10 \mathrm{~ms}$, soma following dendrite), and the peak depolarization at the soma $\left(V_{S}\right)$ was recorded. Bottom, The relative amplitude of summated somatic EPSP was larger in both PT ( $n=12$, green filled circles) and IT ( $n=6$, red empty circles) neurons when the somatic EPSP was simultaneous or followed the dendritic EPSP. Increase in EPSP was calculated as follows: (summated EPSP/somatic EPSP alone). $\boldsymbol{g}$, Bursts of five transferred EPSPs (20-200 $\mathrm{Hz}$, in $20 \mathrm{~Hz}$ increments) were triggered in PT (green) and IT (red) dendrites. $\boldsymbol{h}$, Summation (fifth somatic EPSP/first somatic EPSP) of transferred EPSP bursts in IT (open red symbols) and PT (filled green symbols). $\boldsymbol{i}$, EPSP summation was enhanced at all burst frequencies by $h$-channel blocker ZD7288 (20 $\mu \mathrm{m})$. 


\section{Frequency Components of a Single Synaptic Input}
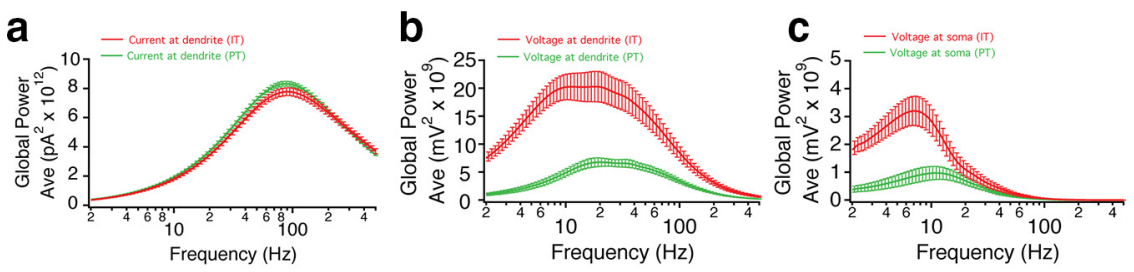

Frequency Components of Bursts of Synaptic Inputs
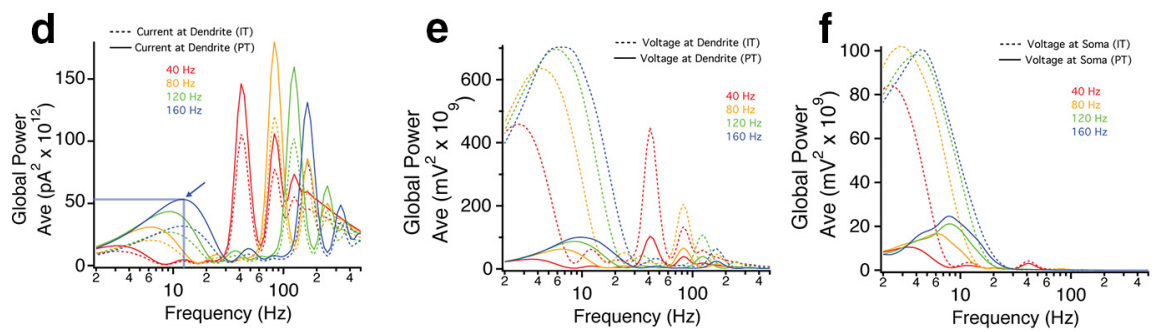

9 Current at Dendrite

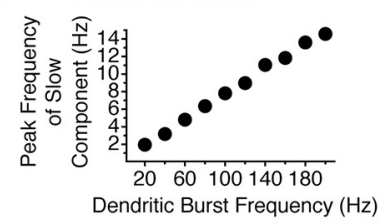

h Current at Dendrite
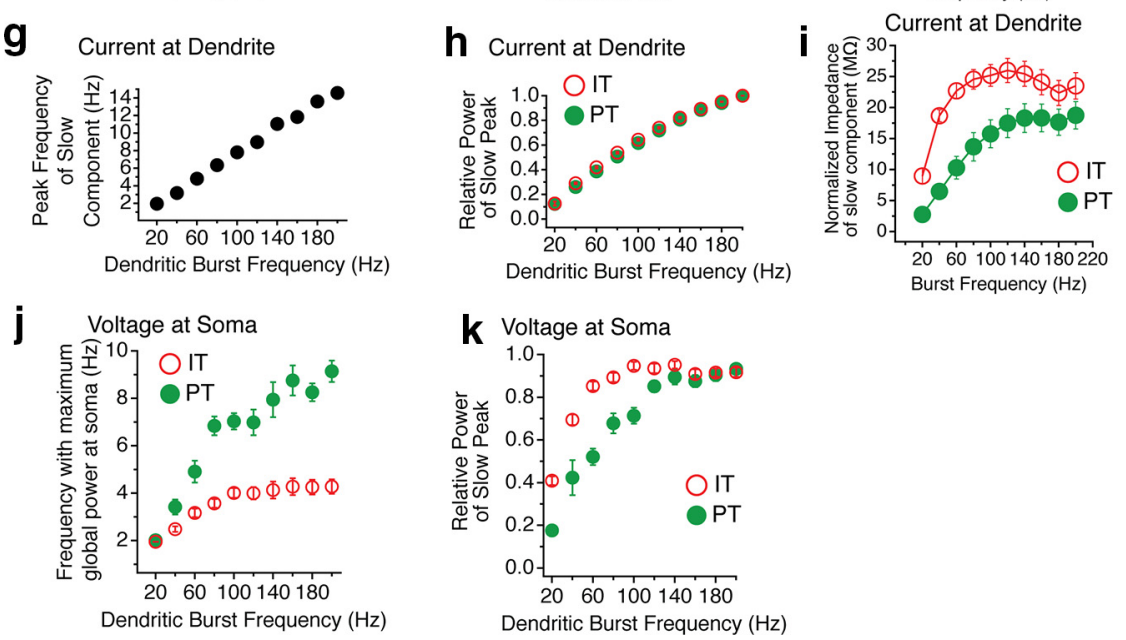

k Voltage at Soma

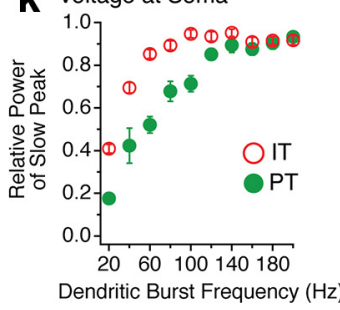

Figure 8. Frequency components of simulated synaptic input. $\boldsymbol{a}-\boldsymbol{c}$, Analysis of single synaptic input. The relative strength of the frequency components of $(\boldsymbol{a})$ a single dendritic simEPSC, $(\boldsymbol{b})$ a single dendritic voltage EPSP, and $(\boldsymbol{c})$ the somatic voltage response to a single dendritic EPSP is represented by the global average power calculated by the CWT of each waveform. The averages and SEM are shown for PT (green, $n=9$ ) and IT (red, $n=9$ ) neurons. $\boldsymbol{d}-\boldsymbol{f}$, Continuous wavelet analysis of bursts of synaptic input for an individual PT (solid lines) and IT (dashed lines) neuron. $\boldsymbol{d}$, The relative strength of frequency components is plotted for the dendritic current waveform from five simEPSCs injections. Four burst frequencies are shown: $40 \mathrm{~Hz}$ (red), $80 \mathrm{~Hz}$ (orange), $120 \mathrm{~Hz}$ (green), $160 \mathrm{~Hz}$ (blue), for one PT (solid lines) and one IT (dashed lines) neuron. In addition to the fast frequency component surrounding each burst frequency, a slow component (arrow) is also present. $\boldsymbol{e}, \boldsymbol{f}$, The relative frequency components of the dendritic $(\boldsymbol{e})$ and somatic $(\boldsymbol{f})$ voltage waveforms in response to bursts of synaptic input to the dendrites are shown as global power averages. $\boldsymbol{g}$, The peak frequency of the slow component increases linearly with input burst frequency. $\boldsymbol{h} \boldsymbol{-} \boldsymbol{k}$, Averages of frequency and relative power across different burst frequencies for PT (green, $n=8$ ) and IT (red, $n=9$ ) neurons. The relative power of the peak from the current (normalized to the maximum power of the slow component for each neuron). $\boldsymbol{i}$, The normalized impedance of the slow component of the peak in $\boldsymbol{h}$, calculated across neurons by taking the transfer impedance from each neuron (e.g., Fig. $6 d$ ) at the peak frequency of the slow component for each burst frequency shown in $\boldsymbol{g}$, weighted for relative power in $\boldsymbol{h}$. $\boldsymbol{j}$, Averages of the frequency with the greatest global power in the somatic voltage waveform shown in $\boldsymbol{f}$. $\boldsymbol{k}$, Relative global power of the slow component of the somatic voltage form at different burst frequencies (different colored traces shown in $\boldsymbol{f}$, normalized to the strongest global power peak.

\section{Projection-specific targeting of afferent inputs}

Direct hippocampal input was more robust in IT neurons than PT neurons, both in terms of the monosynaptic connection rates and the amplitude of responses (Fig. 2). This finding extended to the dendrites, where PT neurons infrequently received direct hippocampal input (Fig. $5 d$ ). In contrast, commissural input directly targeted the dendrites and the soma of both PT and IT neurons, and elicited similar amplitude EPSPs both neuron types. Thus, commissural input appears to directly communicate with PT neurons in a manner that hippocampal input does not. As a result, interhemispheric communication appears to be particularly privileged in directly targeting $\mathrm{mPFC}$ output neurons.

In addition to direct input, many hippocampally driven EPSPs in PT neurons were polysynaptic. Both long-range afferent inputs triggered strong dendritic responses in PT neurons that were reduced considerably in conditions that blocked polysynaptic activity (Fig. 5). These data are consistent with how PT neurons are connected within the PFC microcircuit. Both L2/3 and L5 IT neurons excite PT neurons (Morishima and Kawaguchi, 2006; Morishima et al., 2011; Otsuka and Kawaguchi, 2011; Hirai et al., 2012). Additionally, PT neurons form a high rate of reciprocal connections, meaning that PT neurons receive synaptic input from other PT neurons (Morishima et al., 2011). Although the majority of local connections have been proposed to synapse perisomatically or over the basal dendrites (Morishima and Kawaguchi, 2006; Morishima et al., 2011; Otsuka and Kawaguchi, 2011; Hirai et al., 2012), our data suggest that local connections may also target dendritic compartments. In addition to the direct connections we characterize here, robustly activating commissural input recruits feedforward excitation and inhibition (Lee et al., 2014). Interestingly, feedforward inhibition appears only in PT neurons. As a result, IT neurons may be more likely to form reverberant loops of activity, linking PFC subregions in the contralateral hemisphere. The physiological significance of synchronization across hemispheres for PFC function remains unclear. However, it is notable that disruption of these fibers results in deficits in working memory function (Miu et al., 2006).

\section{Dendritic filtering in PT versus IT neurons}

Neuronal networks that comprise neurons that favor coincidence detection versus temporal integration are hypothesized to selectively perform synchrony and rate coding, respectively (Ratté et al., 2013). Whether neurons function as coincidence detectors or temporal integrators is determined by the set of ion channels dominating their membrane dynamics. When suprathreshold, the operational mode of neurons can also be strongly influenced by voltage-gated and calcium-gated potassium channels, as well as voltage-gated sodium channels (Higgs et al., 2006; Higgs and Spain, 2011). In addition, subthreshold properties influence the suprathreshold firing frequency within particular firing rate and synaptic input regimes (Richardson et al., 2003; Broicher et al., 2012; Das and Narayanan, 2014). 
a

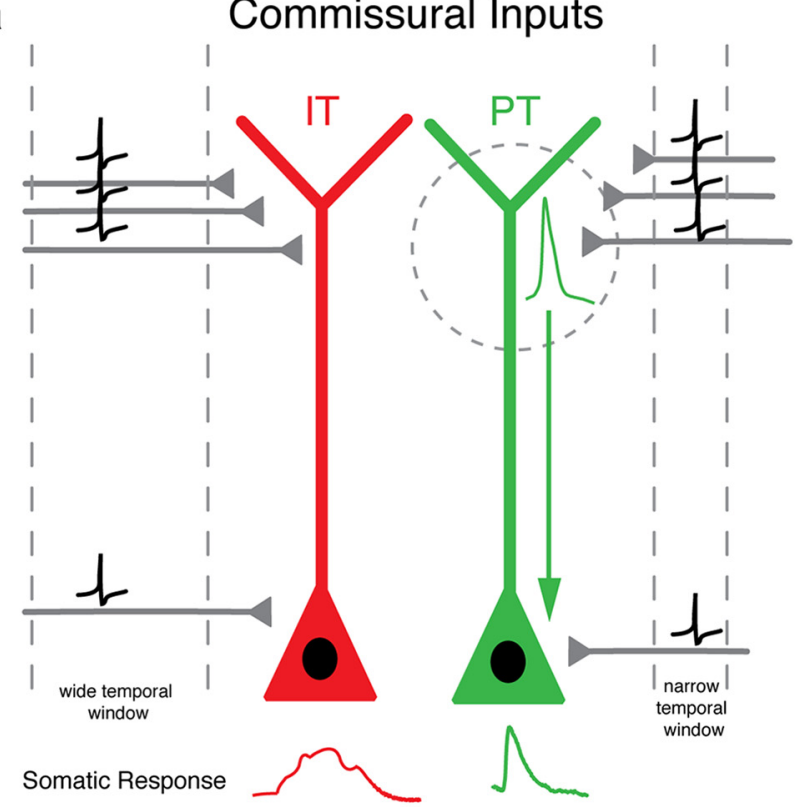

b Hippocampal Inputs

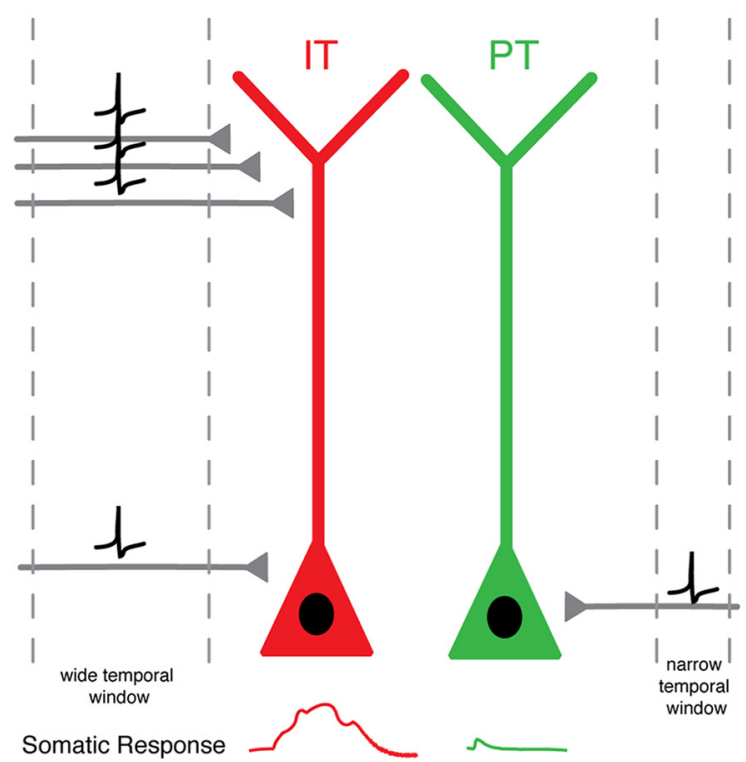

Figure 9. Summary of long-range afferent dendritic processing. Schematic summarizing how dendritic processing affects integration of long-range inputs. $\boldsymbol{a}$, Commissural input (gray axons with spike wave forms illustrated to show near synchronous input) elicits a response in the dendrites in both IT (red) and PT (green) neurons, but distance-dependent delays cause the temporal window (gray dashed lines) in IT neurons to be much wider. Additionally, a dendritic action potential can be elicited in PT, but not IT, neurons. $\boldsymbol{b}$, Hippocampal inputs are mostly absent in PT neurons, causing hippocampal input to primarily be processed by IT neurons, over a wide integration window.

We have found that for subthreshold dendritic inputs, PT neurons act more as coincidence detectors while IT neurons act as temporal integrators. Both neuron categories temporally distorted dendritic signals, but this distortion was greater in IT neurons. PT neurons exhibited distance-dependent temporal normalization, suggesting that synchronous inputs distributed across a wide spatial range could summate at the soma (Fig. $7 d$ ). As a result, PT neurons were tuned to respond selectively to co- incident inputs distributed along their dendritic arbor. We found that h-channel blockade eliminates the coincident detection features that PT neurons display (Figs. 6j,k, 7e,i). Thus, h channels appear to contribute strongly to the mechanism by which PT neurons selectively respond to synchronous input. Similar temporal normalization has been observed in L5B somatosensory neurons and hippocampal CA1 neurons, where it is caused by the increasing density of h current along the apical dendrite (Williams and Stuart, 2002; Vaidya and Johnston, 2013). In contrast, IT neurons did not exhibit temporal normalization: dendritic signals lagged somatic ones across all frequencies. These delays made IT neurons integrate signals that were injected both at the dendrite and soma over a wider temporal window (Fig. $7 f$ ). While our data are limited to only two locations (i.e., at the nexus of the apical dendrite and at the soma), they suggest that IT neurons are more sensitive to spatially distributed signals along their dendritic arbor.

A few important caveats must be considered in our characterization of the integrative properties of IT versus PT neurons. To examine synaptic integration, we chose to inject identical simulated synaptic conductances into PT and IT neurons. Even when $\mathrm{PT}$ and IT neurons receive identical synaptic input, the dendritic voltage response they exhibited was distinct (Fig. 7b). Of course, we cannot exclude the possibility the synaptic contacts from hippocampal or commissural inputs onto PT versus IT dendrites might additionally possess different physiological properties. For example, the amplitude, kinetics, and/or ratio of AMPA to NMDA receptors may differ depending upon the postsynaptic neuron and presynaptic input. Furthermore, it is possible that with the parallel recruitment of local interneurons included (Lee et al., 2014), the integrative properties of PT versus IT neurons might also change. Inhibitory interneurons alter how neurons integrate inputs arriving at different dendritic compartments (Palmer et al., 2012; Chiu et al., 2013). Nonetheless, we find that without any of these distinctions included, the dendritic intrinsic properties alone can alter the integration of synaptic signals.

The distinct filtering properties of PT and IT dendrites suggest that how long-range afferent inputs are processed depends upon which neuron type is targeted. Commissural inputs to the mPFC would be processed in parallel: sensitive to both highly synchronous (via PT dendrites) and temporally distributed (via IT dendrites) signals (Fig. 9). In contrast, direct hippocampal input, which primarily targeted IT dendrites, would be most responsive to temporally distributed inputs, particularly within the gamma frequency range, one of the noted correlates of working memory in mPFC (Howard et al., 2003; Roux et al., 2012). The IT somatic response to a wide range of inputs $(100-200 \mathrm{~Hz})$ displayed similar temporal components, always resulting in somatic waveform that was primarily $4 \mathrm{~Hz}$. In light of this, it is intriguing that a similar frequency synchronizes activity between the hippocampus and the PFC immediately before behavioral choice (Fujisawa and Buzsáki, 2011). Our findings suggest that one mechanism by which a cortical region can extract particular information from an afferent input is by selectively targeting the dendrites of neurons with disparate filtering properties.

\section{References}

Adhikari A, Topiwala MA, Gordon JA (2011) Single units in the medial prefrontal cortex with anxiety-related firing patterns are preferentially influenced by ventral hippocampal activity. Neuron 71:898-910. CrossRef Medline

Anderson CT, Sheets PL, Kiritani T, Shepherd GM (2010) Sublayer-specific 
microcircuits of corticospinal and corticostriatal neurons in motor cortex. Nat Neurosci 13:739-744. CrossRef Medline

Barth AM, Vizi ES, Zelles T, Lendvai B (2008) Alpha2-adrenergic receptors modify dendritic spike generation via $\mathrm{HCN}$ channels in the prefrontal cortex. J Neurophysiol 99:394-401. Medline

Benchenane K, Peyrache A, Khamassi M, Tierney PL, Gioanni Y, Battaglia FP, Wiener SI (2010) Coherent theta oscillations and reorganization of spike timing in the hippocampal-prefrontal network upon learning. Neuron 66:921-936. CrossRef Medline

Berger T, Larkum ME, Lüscher HR (2001) High I(h) channel density in the distal apical dendrite of layer $\mathrm{V}$ pyramidal cells increases bidirectional attenuation of EPSPs. J Neurophysiol 85:855-868. Medline

Broicher T, Malerba P, Dorval AD, Borisyuk A, Fernandez FR, White JA (2012) Spike phase locking in CA1 pyramidal neurons depends on background conductance and firing rate. J Neurosci 32:14374-14388. CrossRef Medline

Chiu CQ, Lur G, Morse TM, Carnevale NT, Ellis-Davies GC, Higley MJ (2013) Compartmentalization of GABAergic inhibition by dendritic spines. Science 340:759-762. CrossRef Medline

Cowan RL, Wilson CJ (1994) Spontaneous firing patterns and axonal projections of single corticostriatal neurons in the rat medial agranular cortex. J Neurophysiol 71:17-32. Medline

Das A, Narayanan R (2014) Active dendrites regulate spectral selectivity in location-dependent spike initiation dynamics of hippocampal model neurons. J Neurosci 34:1195-1211. CrossRef Medline

Dégenètais E, Thierry AM, Glowinski J, Gioanni Y (2003) Synaptic influence of hippocampus on pyramidal cells of the rat prefrontal cortex: an in vivo intracellular recording study. Cereb Cortex 13:782-792. CrossRef Medline

Dembrow NC, Chitwood RA, Johnston D (2010) Projection-specific neuromodulation of medial prefrontal cortex neurons. J Neurosci 30:1692216937. CrossRef Medline

Dickerson DD, Wolff AR, Bilkey DK (2010) Abnormal long-range neural synchrony in a maternal immune activation animal model of schizophrenia. J Neurosci 30:12424-12431. CrossRef Medline

Fujisawa S, Buzsáki G (2011) A $4 \mathrm{~Hz}$ oscillation adaptively synchronizes prefrontal, VTA, and hippocampal activities. Neuron 72:153-165. CrossRef Medline

Godsil BP, Kiss JP, Spedding M, Jay TM (2013) The hippocampalprefrontal pathway: the weak link in psychiatric disorders? Eur Neuropsychopharmacol 23:1165-1181. CrossRef Medline

Golding NL, Staff NP, Spruston N (2002) Dendritic spikes as a mechanism for cooperative long-term potentiation. Nature 418:326-331. CrossRef Medline

Golding NL, Mickus TJ, Katz Y, Kath WL, Spruston N (2005) Factors mediating powerful voltage attenuation along CA1 pyramidal neuron dendrites. J Physiol 568:69-82. CrossRef Medline

Harnett MT, Xu NL, Magee JC, Williams SR (2013) Potassium channels control the interaction between active dendritic integration compartments in layer 5 cortical pyramidal neurons. Neuron 79:516-529. CrossRef Medline

Higgs MH, Spain WJ (2009) Conditional bursting enhances resonant firing in neocortical layer 2-3 pyramidal neurons. J Neurosci 29:1285-1299. CrossRef Medline

Higgs MH, Spain WJ (2011) Kv1 channels control spike threshold dynamics and spike timing in cortical pyramidal neurones. J Physiol 589:51255142. CrossRef Medline

Higgs MH, Slee SJ, Spain WJ (2006) Diversity of gain modulation by noise in neocortical neurons: regulation by the slow afterhyperpolarization conductance. J Neurosci 26:8787-8799. CrossRef Medline

Hirai Y, Morishima M, Karube F, Kawaguchi Y (2012) Specialized cortical subnetworks differentially connect frontal cortex to parahippocampal areas. J Neurosci 32:1898-1913. CrossRef Medline

Hoover WB, Vertes RP (2007) Anatomical analysis of afferent projections to the medial prefrontal cortex in the rat. Brain Struct Funct 212:149-179. CrossRef Medline

Hoppenbrouwers SS, De Jesus DR, Sun Y, Stirpe T, Hofman D, McMaster J, Hughes G, Daskalakis ZJ, Schutter DJ (2014) Abnormal interhemispheric connectivity in male psychopathic offenders. J Psychiatry Neurosci 39:22-30. CrossRef Medline

Howard MW, Rizzuto DS, Caplan JB, Madsen JR, Lisman J, AschenbrennerScheibe R, Schulze-Bonhage A, Kahana MJ (2003) Gamma oscillations correlate with working memory load in humans. Cereb Cortex 13:13691374. CrossRef Medline

Jay TM, Glowinski J, Thierry AM (1989) Selectivity of the hippocampal projection to the prelimbic area of the prefrontal cortex in the rat. Brain Res 505:337-340. CrossRef Medline

Kalmbach BE, Chitwood RA, Dembrow NC, Johnston D (2013) Dendritic generation of mGluR-mediated slow afterdepolarization in layer 5 neurons of prefrontal cortex. J Neurosci 33:13518-13532. CrossRef Medline

Larkum M (2013) A cellular mechanism for cortical associations: an organizing principle for the cerebral cortex. Trends Neurosci 36:141-151. CrossRef Medline

Larkum ME, Zhu JJ, Sakmann B (1999a) A new cellular mechanism for coupling inputs arriving at different cortical layers. Nature 398:338-341. CrossRef Medline

Larkum ME, Kaiser KM, Sakmann B (1999b) Calcium electrogenesis in distal apical dendrites of layer 5 pyramidal cells at a critical frequency of back-propagating action potentials. Proc Natl Acad Sci U S A 96:1460014604. CrossRef Medline

Larkum ME, Senn W, Lüscher HR (2004) Top-down dendritic input increases the gain of layer 5 pyramidal neurons. Cereb Cortex 14:10591070. CrossRef Medline

Lee AT, Gee SM, Vogt D, Patel T, Rubenstein JL, Sohal VS (2014) Pyramidal neurons in prefrontal cortex receive subtype-specific forms of excitation and inhibition. Neuron 81:61-68. CrossRef Medline

Little JP, Carter AG (2012) Subcellular synaptic connectivity of layer 2 pyramidal neurons in the medial prefrontal cortex. J Neurosci 32:12808 12819. CrossRef Medline

Magee JC, Cook EP (2000) Somatic EPSP amplitude is independent of synapse location in hippocampal pyramidal neurons. Nat Neurosci 3:895903. CrossRef Medline

Mao T, Kusefoglu D, Hooks BM, Huber D, Petreanu L, Svoboda K (2011) Long-range neuronal circuits underlying the interaction between sensory and motor cortex. Neuron 72:111-123. CrossRef Medline

Miu AC, Heilman RM, Paşca SP, Stefan CA, Spânu F, Vasiu R, Olteanu AI, Miclea M (2006) Behavioral effects of corpus callosum transection and environmental enrichment in adult rats. Behav Brain Res 172:135-144. CrossRef Medline

Morishima M, Kawaguchi Y (2006) Recurrent connection patterns of corticostriatal pyramidal cells in frontal cortex. J Neurosci 26:4394-4405. CrossRef Medline

Morishima M, Morita K, Kubota Y, Kawaguchi Y (2011) Highly differentiated projection-specific cortical subnetworks. J Neurosci 31:1038010391. CrossRef Medline

Narayanan R, Johnston D (2008) The h channel mediates location dependence and plasticity of intrinsic phase response in rat hippocampal neurons. J Neurosci 28:5846-5860.

Nevian T, Larkum ME, Polsky A, Schiller J (2007) Properties of basal dendrites of layer 5 pyramidal neurons: a direct patch-clamp recording study. Nat Neurosci 10:206-214. CrossRef Medline

Otsuka T, Kawaguchi Y (2008) Firing-pattern-dependent specificity of cortical excitatory feed-forward subnetworks. J Neurosci 28:11186-11195. CrossRef Medline

Otsuka T, Kawaguchi Y (2011) Cell diversity and connection specificity between callosal projection neurons in the frontal cortex. J Neurosci 31: 3862-3870. CrossRef Medline

Oviedo HV, Bureau I, Svoboda K, Zador AM (2010) The functional asymmetry of auditory cortex is reflected in the organization of local cortical circuits. Nat Neurosci 13:1413-1420. CrossRef Medline

Palmer LM, Schulz JM, Murphy SC, Ledergerber D, Murayama M, Larkum ME (2012) The cellular basis of GABAB-mediated interhemispheric inhibition. Science 335:989-993. CrossRef Medline

Parent MA, Wang L, Su J, Netoff T, Yuan LL (2010) Identification of the hippocampal input to medial prefrontal cortex in vitro. Cereb Cortex 20:393-403. CrossRef Medline

Petreanu L, Huber D, Sobczyk A, Svoboda K (2007) Channelrhodopsin-2assisted circuit mapping of long-range callosal projections. Nat Neurosci 10:663-668. CrossRef Medline

Ratté S, Hong S, De Schutter E, Prescott SA (2013) Impact of neuronal properties on network coding: roles of spike initiation dynamics and robust synchrony transfer. Neuron 78:758-772. CrossRef Medline 
Richardson MJE, Brunel N, Hakim V (2003) From subthreshold to firing-rate resonance. J Neurophysiol 89:2538-2554. CrossRef Medline

Roux F, Wibral M, Mohr HM, Singer W, Uhlhaas PJ (2012) Gamma-band activity in human prefrontal cortex codes for the number of relevant items maintained in working memory. J Neurosci 32:12411-12420. CrossRef Medline

Sheets PL, Suter BA, Kiritani T, Chan CS, Surmeier DJ, Shepherd GM (2011) Corticospinal-specific HCN expression in mouse motor cortex: Ihdependent synaptic integration as a candidate microcircuit mechanism involved in motor control. J Neurophysiol 106:2216-2231. CrossRef Medline

Sigurdsson T, Stark KL, Karayiorgou M, Gogos JA, Gordon JA (2010) Impaired hippocampal-prefrontal synchrony in a genetic mouse model of schizophrenia. Nature 464:763-767. CrossRef Medline

Torrence C, Compo GP (1998) A practical guide to wavelet analysis. Bull Amer Meteor Soc 79:61-78. CrossRef

Tseng KY, Lewis BL, Hashimoto T, Sesack SR, Kloc M, Lewis DA, O’Donnell P (2008) A neonatal ventral hippocampal lesion causes functional deficits in adult prefrontal cortical interneurons. J Neurosci 28:12691-12699. CrossRef Medline
Vaidya SP, Johnston D (2013) Temporal synchrony and gamma-to-theta power conversion in the dendrites of CA1 pyramidal neurons. Nat Neurosci 16:1812-1820. CrossRef Medline

Watanabe S, Hoffman DA, Migliore M, Johnston D (2002) Dendritic K+ channels contribute to spike-timing dependent long-term potentiation in hippocampal pyramidal neurons. Proc Natl Acad Sci U S A 99:83668371. CrossRef Medline

Wheeler AL, Chakravarty MM, Lerch JP, Pipitone J, Daskalakis ZJ, Rajji TK, Mulsant BH, Voineskos AN (2014) Disrupted prefrontal interhemispheric structural coupling in schizophrenia related to working memory performance. Schizophr Bull 40:914-924. CrossRef Medline

Williams SR, Mitchell SJ (2008) Direct measurement of somatic voltageclamperrors in central neurons. Nat Neurosci 11:790-798. CrossRef Medline

Williams SR, Stuart GJ (2000) Site independence of EPSP time course is mediated by dendritic $\mathrm{I}(\mathrm{h})$ in neocortical pyramidal neurons. J Neurophysiol 83:3177-3182. Medline

Williams SR, Stuart GJ (2002) Dependence of EPSP efficacy on synapse location in neocortical pyramidal neurons. Science 295:1907-1910. CrossRef Medline 